\title{
The Impact of Tropical Precipitation on Summertime Euro-Atlantic Circulation via a Circumglobal Wave Train
}

\author{
Christopher H. O'Reilly, Tim WoOllings, And LAure ZANnA \\ Atmospheric, Oceanic and Planetary Physics, Department of Physics, University of Oxford, Oxford, United Kingdom
}

ANTJE WEISHEIMER

European Centre for Medium-Range Weather Forecasts, and National Centre for Atmospheric Science, Department of Physics, University of Oxford, Oxford, United Kingdom

(Manuscript received 5 July 2017, in final form 28 March 2018)

\begin{abstract}
The influence of tropical precipitation variability on summertime seasonal circulation anomalies in the Euro-Atlantic sector is investigated. The dominant mode of the maximum covariance analysis (MCA) between the Euro-Atlantic circulation and tropical precipitation reveals a cyclonic anomaly over the extratropical North Atlantic, contributing to anomalously wet conditions over western Europe and dry conditions over eastern Europe and Scandinavia (in the positive phase). The related mode of tropical precipitation variability is associated with tropical Pacific SST anomalies and is closely linked to the El Niño-Southern Oscillation (ENSO). The second MCA mode consists of weaker tropical precipitation anomalies but with a stronger extratropical signal that reflects internal atmospheric variability. The teleconnection mechanism is tested in barotropic model simulations, which indicate that the observed link between the dominant mode of tropical precipitation and the Euro-Atlantic circulation anomalies is largely consistent with linear Rossby wave dynamics. The barotropic model response consists of a circumglobal wave train in the extratropics that is primarily forced by divergence anomalies in the eastern tropical Pacific. Both the eastward and westward group propagation of the Rossby waves are found to be important in determining the circulation response over the Euro-Atlantic sector. The mechanism was also analyzed in an operational seasonal forecasting system, ECMWF's System 4. While System 4 is well able to reproduce and skillfully forecast the tropical precipitation, the extratropical circulation response is absent over the Euro-Atlantic region, which is likely related to biases in the Asian jet stream.
\end{abstract}

\section{Introduction}

Large-scale atmospheric circulation anomalies exhibit a strong control on interannual variability of European summertime temperature and precipitation (Folland et al. 2009; Bladé et al. 2012). For example, large-scale circulation anomalies are responsible for very wet summers (Yiou and Cattiaux 2013), as well as exceptionally hot and dry summers over continental Europe (Fischer et al. 2007). However, despite the demonstrated progress in seasonal forecasting skill of Euro-Atlantic circulation in winter (Scaife et al. 2014; Dunstone et al. 2016; Stockdale et al. 2015; Weisheimer et al. 2017; Riddle et al. 2013), the skill is comparatively low in summertime seasonal forecasts (Weisheimer and

Corresponding author: Christopher H. O'Reilly, christopher. oreilly@physics.ox.ac.uk
Palmer 2014; MacLachlan et al. 2015). Understanding the predictable drivers of summertime circulation anomalies over the Euro-Atlantic sector, therefore, is important in helping to improve seasonal forecasting capabilities.

Some predictable drivers of circulation anomalies over the Euro-Atlantic sector have been highlighted in previous studies. The Atlantic multidecadal oscillation (e.g., Enfield et al. 2001) in sea surface temperatures (SSTs) has been shown to be associated with a cyclonic circulation anomaly over northwest Europe on decadal time scales (Sutton and Hodson 2005; Knight et al. 2005, 2006; Sutton and Dong 2012; O'Reilly et al. 2017b), broadly consistent with a linear baroclinic response to extratropical Atlantic SST anomalies (Ghosh et al. 2017). However, Atlantic SST anomalies also appear to influence summertime circulation on interannual time scales. Gastineau and Frankignoul (2015) used a 
maximum covariance analysis on observational data to show that a tripolar SST pattern in spring tends to be followed by atmospheric circulation anomalies over the east Atlantic, although the relative importance of the tropical and subpolar-gyre SST anomalies is unclear. Dong et al. (2013) found that interannual shifts in the North Atlantic summer storm track are significantly related to extratropical SST anomalies in the spring and that the summer SST anomalies themselves were consistent with the ocean exerting some control on the atmosphere. It has been shown that recent Arctic sea ice anomalies might be responsible for some summertime trends in atmospheric circulation over the Euro-Atlantic region (Screen 2013; Petrie et al. 2015), although there is only limited observational evidence that sea ice anomalies significantly influence circulation variability on interannual time scales (Wu et al. 2013).

Seasonal forecasts in winter derive much of their skill from tropical SST anomalies, particularly in the Pacific, and the associated teleconnection patterns (Smith et al. 2012). Tropical SST anomalies, such as those associated with the El Niño-Southern Oscillation (ENSO), drive convective precipitation and latent heating anomalies, which generate Rossby waves that propagate into the extratropics (e.g., Hoskins and Karoly 1981; Sardeshmukh and Hoskins 1988; Trenberth et al. 1998). Less attention has been given to teleconnections from the tropics to the Euro-Atlantic sector in the summer. During the summer, tropical SST anomalies tend to be smaller, along with weaker (or even reversed) vorticity gradients upon which Rossby waves propagate into the extratropics, resulting in weaker associated circulation anomalies than in winter (Hoskins and Ambrizzi 1993; Ambrizzi et al. 1995). Nonetheless, in observations there does appear to be a teleconnection between ENSO and the Euro-Atlantic region in summer, with impacts for precipitation in some parts of Europe (Ropelewski and Halpert 1987; Park 2004; Shaman and Tziperman 2011; Shaman 2014b). Shaman (2014a) analyzed the response of a linear barotropic model to ENSO forcing in the late summer [i.e., July-September (JAS)]; however, the model response over the Euro-Atlantic sector is seemingly different to the apparent influence of ENSO over the period 1949-2011 [cf. Figs. 1, 3, and 8 in Shaman (2014a)]. In other seasons though, Shaman (2014a) found that the atmospheric circulation anomalies associated with ENSO were found to be in reasonable agreement with the response of a barotropic model. In this study we investigate how summer (JJA) tropical precipitation anomalies influence Euro-Atlantic circulation over the satellite period (1979-2016) and test the mechanism of the observed teleconnection in a simple barotropic model, which is found to perform reasonably well. A comparison with the analysis of Shaman (2014a) suggests that there is a strong dependence on time period, which we discuss in section 6 .

A direct statistical method of estimating the seasonal extratropical response to tropical forcing is to analyze covariability of tropical precipitation and extratropical circulation anomalies. Ding et al. (2011) performed a maximum covariance analysis, using a reconstructed global precipitation dataset and a reanalysis dataset between 1948 and 2009 to analyze the global circulation response to tropical precipitation. Their analysis revealed two "circumglobal" covarying modes of tropical precipitation and extratropical circulation. In this study, we take a similar approach to Ding et al. (2011), but here we analyze variability in tropical precipitation that specifically impacts circulation in the Euro-Atlantic region. The dataset, methods, and idealized models used in our study are described in the following section. We then discuss results from observations and reanalysis data over the satellite period in section 3. The results from the observations are compared with results from an idealized barotropic model in section 4 . In section 5 we move on to compare the results with output from an operational seasonal forecast model. A summary of our findings and further discussion follows in section 6 .

\section{Data and methods}

\section{a. Observational and reanalysis data}

We use the Global Precipitation Climatology Project (GPCP) monthly precipitation dataset for the summer months JJA over the 38-yr period 1979-2016. The GPCP precipitation data are provided on a $2.5^{\circ} \times 2.5^{\circ}$ grid and are produced using data from rain gauge stations and satellite observations (Adler et al. 2003). While results from the GPCP precipitation data are presented throughout, the analysis was also carried out using the CPC Merged Analysis of Precipitation (CMAP; Xie and Arkin (1997)) dataset and the results presented here are insensitive to the use of either GPCP or CMAP data. We also use data from the ECMWF ERA-Interim reanalysis, also over the period 1979-2016 (Dee et al. 2011). SST data were taken from the NOAA Extended Reconstructed SST (ERSST), version 4 dataset (Huang et al. 2015), over the same period as the precipitation and reanalysis datasets.

For the storm-track analysis in section 3, high- and low-pass-filtered variables are calculated using an 8-day Lanczos filter (Duchon 1979) with 15 weights on daily data. The high- and low-pass-filtered variables are denoted by the subscripts $h$ and $l$, respectively. 


\section{b. Barotropic model}

In this study we employ an idealized model to examine the mechanisms of teleconnections to the EuroAtlantic sector. The model integrates the barotropic vorticity equation on a sphere (following Hoskins and Ambrizzi 1993):

$$
\left(\frac{\partial}{\partial t}+\mathbf{u}_{\psi} \cdot \nabla\right) \zeta=F-\lambda \zeta-\mu \nabla^{4} \zeta
$$

where $\mathbf{u}_{\psi}$ is the rotational velocity field, $\zeta$ is the absolute vorticity (the sum of planetary and relative vorticity components), $F$ is a constant forcing term, $\lambda$ is a linear damping rate with a time scale of 10 days, and $\mu=2.4 \times 10^{16} \mathrm{~m}^{4} \mathrm{~s}^{-1}$ is a biharmonic diffusion coefficient. The equation is solved using spectral harmonics with a triangular truncation at wavenumber 42 (i.e., T42). The forcing is decomposed into two terms, $F=\bar{F}+F^{\prime}$, where $\bar{F}$ is selected to exactly maintain the basic state, which is taken to be the climatological vorticity field at $250 \mathrm{hPa}$.

The anomalous forcing, $F^{\prime}$, is selected to mimic the forcing of the barotropic vorticity equation by divergent outflow in the tropics. Following, Sardeshmukh and Hoskins (1988), the linearized Rossby wave source anomaly $S^{\prime}$ is given by

$$
S^{\prime}=-\mathbf{u}_{\chi}^{\prime} \cdot \nabla \bar{\zeta}-\overline{\mathbf{u}_{\chi}} \cdot \nabla \zeta^{\prime}-\bar{\zeta} D^{\prime}-\zeta^{\prime} \bar{D},
$$

where $\mathbf{u}_{\chi}$ is the divergent velocity field and $D=\nabla \cdot \mathbf{u}_{\chi}$ is the divergence. Here overbars and primes denote climatological and anomaly fields, respectively. In this study we force the model with a Rossby wave source anomaly due only to anomalous divergence. We ignore terms due to anomalous vorticity, since these correspond to the circulation response we are assessing. The forcing term therefore reduces to

$$
S^{\prime}=-\mathbf{u}_{\chi}^{\prime} \cdot \nabla \bar{\zeta}-\bar{\zeta} D^{\prime} \approx-\bar{\zeta} D^{\prime}=F^{\prime}
$$

The divergent wind term is neglected for the rest of our study as this term was found to be over an order of magnitude smaller than the divergence term and including this term in the subtropics (i.e., up to about $25^{\circ} \mathrm{N}$ ) had only a negligible influence on the results.

The choice of the 250-hPa level for the basic state is a source of uncertainty in barotropic model experiments (e.g., Held and Kang 1987); however, our results were not found to be particularly qualitatively different for basic states chosen between 350 and $200 \mathrm{hPa}$. The basic state was taken from the upper troposphere because this is where anomalous tropical forcing (via divergent outflow) is strongest (e.g., Krishnamurti et al. 2013). The vorticity gradients, upon which the signal propagates out of the tropics, are also significantly stronger in the upper troposphere. We found it was necessary that the basic state includes these strong waveguides (which are not present lower in the troposphere) to achieve a reasonable response, in terms of both amplitude and pattern.

The model was initialized from the basic state and integrated forward for 30 days. The response becomes quasi-stationary after about two weeks, so the stationary response to forcing is presented as the average over the period 16-20 days.

Additional simulations were employed using sponge layers to strongly damp anomalous vorticity at certain longitudes. These sponge layers have a Gaussian longitudinal profile, with a width of $\sigma=25^{\circ}$. In the center of the sponge layer the damping time scale is about $2 \mathrm{~h}$, decaying away from the central longitude following the Gaussian profile. These were found to be sufficient to successfully damp group propagation across the longitude of the sponge layer.

\section{Observed tropical precipitation variability and associated extratropical circulation}

\section{a. First MCA mode and first EOF of tropical precipitation}

We first use observational datasets to isolate the dominant modes of covariability between seasonal mean tropical precipitation and Euro-Atlantic circulation anomalies, using geopotential height at the $500-\mathrm{hPa}$ level in the midtroposphere (i.e., Z500). To do this, we initially take a similar approach to Ding et al. (2011) and perform a maximum covariance analysis (MCA; Bretherton et al. 1992) between global tropical precipitation anomalies over $15^{\circ} \mathrm{S}-30^{\circ} \mathrm{N}$ and detrended geopotential height anomalies at the $500-\mathrm{hPa}$ level in the midtroposphere (i.e., Z500) over the Euro-Atlantic sector $\left(30^{\circ}-70^{\circ} \mathrm{N}, 90^{\circ} \mathrm{W}-30^{\circ} \mathrm{E}\right.$,). The first MCA mode explains $43 \%$ of the squared covariance and the expansion coefficient time series are reasonably well correlated $(r=0.63)$. The precipitation anomaly associated with the first MCA mode is almost identical to the first EOF of tropical precipitation (which explains $22 \%$ of the total variance), with a correlation of $r=0.97$ between the respective time series. The eigenvalue of the first EOF of summertime tropical precipitation is well separated from the other eigenvalues according to the "rule of thumb" of North et al. (1982). Correlations between gridpoint precipitation and the first MCA mode and first EOF pattern are shown in Figs. 1a,b, respectively. The Z500 anomalies associated with the first MCA mode are also shown in the Euro-Atlantic 

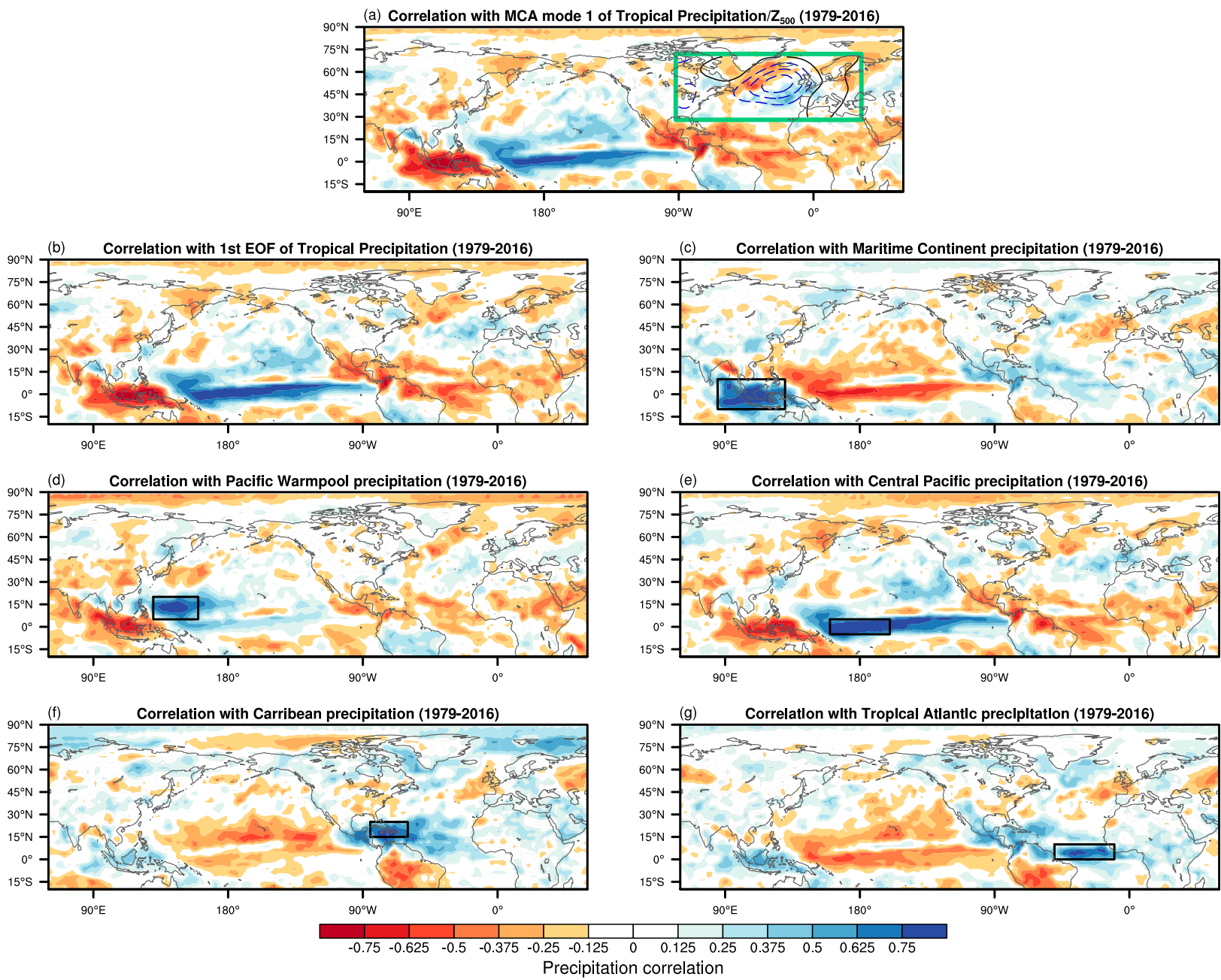

FIG. 1. Correlation of the summer (JJA) GPCP precipitation anomaly with indices of (a) first mode from a maximum covariance analysis (MCA) between tropical precipitation and Z500 over the Euro-Atlantic sector, (b) first EOF of tropical precipitation $\left(15^{\circ} \mathrm{S}-\right.$ $30^{\circ} \mathrm{N}$ ), (c) Maritime Continent precipitation, (d) Pacific warm pool precipitation, (e) central Pacific precipitation, (f) Caribbean precipitation, and (g) tropical Atlantic precipitation. The contours in (a) show the regression of Z500 anomaly onto the normalized first precipitation mode time series from the MCA, with a contour interval of $5 \mathrm{~m}$. The first MCA mode explains $43 \%$ of the squared covariance between the tropical precipitation $\left(15^{\circ} \mathrm{S}-30^{\circ} \mathrm{N}\right)$ and the $\mathrm{Z} 500$ over the Euro-Atlantic region. The Euro-Atlantic region used for the MCA is shown by the green box in (a). Note that Z500 anomaly associated with the first MCA mode is only shown in the EuroAtlantic region.

region used for the MCA (Fig. 1a). To assess the extent to which this pattern of tropical precipitation is coherent, as opposed to simply an artifact of the MCA, we also calculated gridpoint correlation maps with areaaveraged precipitation indices based on the anomaly centers in Fig. 1a, which are shown in the additional panels in Fig. 1. The first MCA mode and first EOF appear to be related to each of the area-averaged precipitation indices-most clearly those over the Maritime Continent, central Pacific, and tropical Atlantic - indicating the global nature of this dominant mode of tropical precipitation variability. Given the equivalence of the first MCA mode and the first EOF of tropical precipitation, we focus much of our analysis on the anomalies associated with the first EOF of tropical precipitation.

The precipitation anomaly regressed onto the normalized principle component time series of the first EOF of summertime tropical precipitation is shown in Fig. 2a. To estimate the extratropical circulation anomalies associated with the first EOF of tropical precipitation, we regressed atmospheric circulation anomalies onto the normalized time series and these are also shown in Fig. 2. These time series exhibit no significant autocorrelation, therefore, the significance of the regression and correlation statistics quoted hereafter 

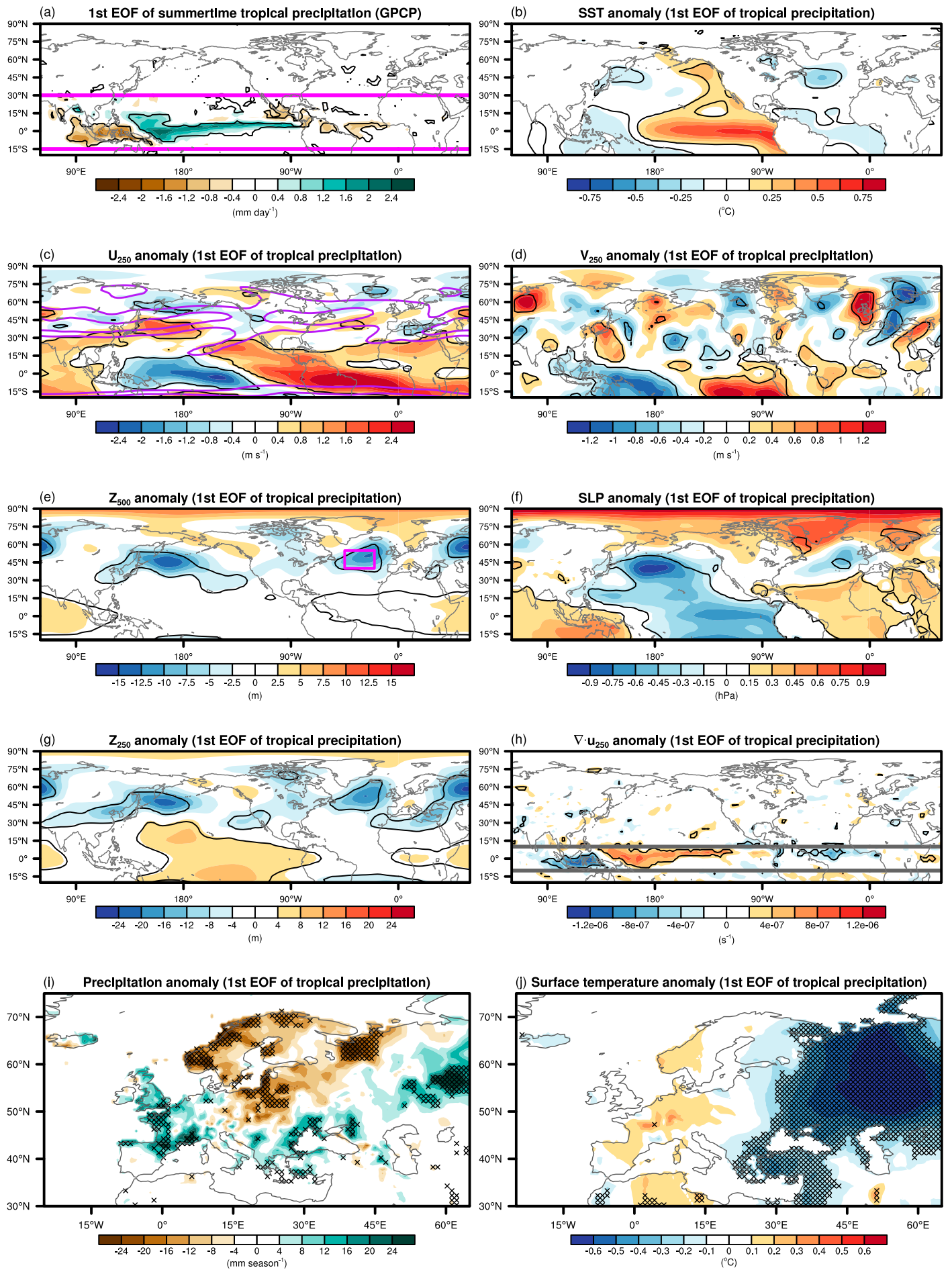

FIG. 2. (a) Precipitation anomalies regressed onto the normalized principal component time series of the first EOF of boreal summer (i.e., JJA) over the tropics (defined as $15^{\circ} \mathrm{S}-30^{\circ} \mathrm{N}$, shown by the magenta lines) from the GPCP dataset (1979-2016). Also shown are anomaly fields (linearly detrended) regressed onto the normalized first principal component time series of tropical precipiation: (b) SST; (c) $u(250 \mathrm{hPa})$; (d) $v(250 \mathrm{hPa}$; (e) Z500; (f) $v$ (700 hPa); (g) $Z(250 \mathrm{hPa})$; and (h) divergence, $\nabla \cdot \mathbf{u}(250 \mathrm{hPa})$. Also shown are (i) precipitation and (j) surface air temperature anomalies from the CRU-TS gridded dataset (1979-2015) regressed onto the tropical precipitation index. Units are shown per standard deviation of the normalized principal component. The black contours in (b),(c),(d),(e),(f),(g) and stippling in (i),(j) indicate where the anomalies are significant at the $5 \%$ level, using a two-sided $t$ test. The black contours in (a) and (h) indicate where the anomalies are significant at the $1 \%$ level. The region outlined by the gray box in (h) shows the region identified as active tropical precipitation forcing. The magenta box in (e) shows the used to define the North Atlantic Z500 index shown in Fig. 3. In (c) the purple contours show the climatological $u(250 \mathrm{hPa})$ at 10 and $20 \mathrm{~m} \mathrm{~s}^{-1}$. 


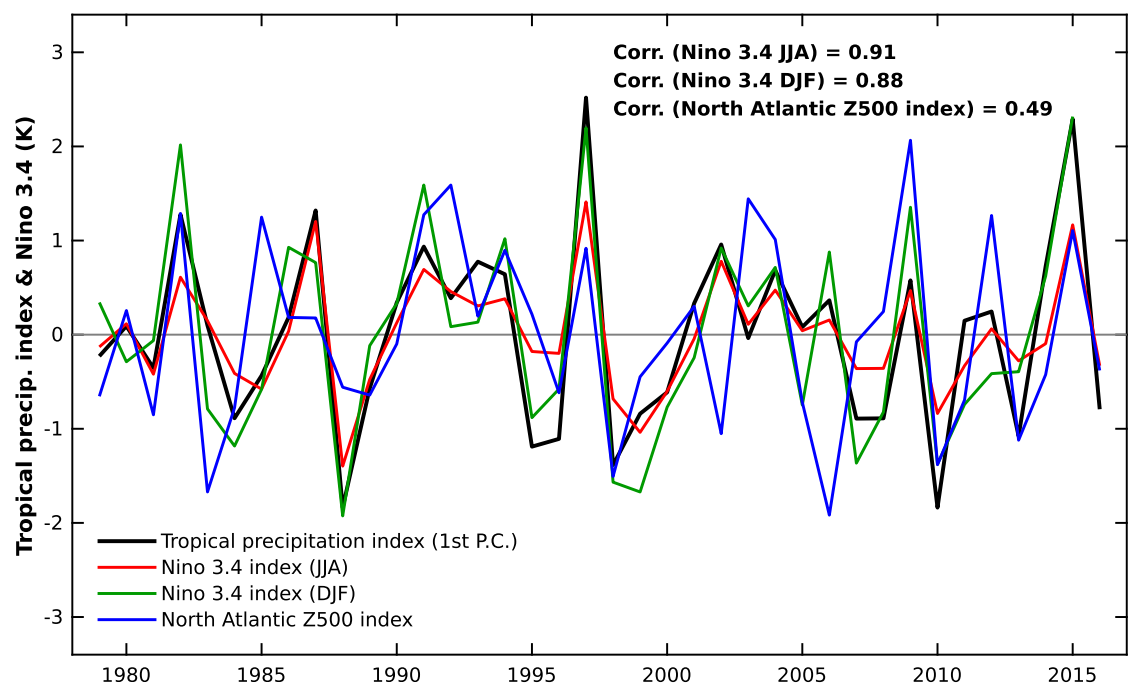

FIG. 3. Time series of the tropical precipitation index (i.e., .the normalized first principal component time series of tropical precipitation) is plotted in black. Also plotted are the Niño3.4 index for the summer (JJA, in red) and the following winter (DJF, in green). A normalized index of summer North Atlantic Z500, averaged over the region outlined in Fig. $2 \mathrm{e}\left(40^{\circ}-55^{\circ} \mathrm{N}\right.$, $45^{\circ}-20^{\circ} \mathrm{W}$ ) and multiplied by -1 , is plotted in blue. Correlations between the tropical precipitation index and the other time series are also shown; all correlation values are significant at the $1 \%$ level according to a two-sided $t$ test.

were calculated using a Student's $t$ test with each year taken to be one degree of freedom. There are significant circulation anomalies across much of the extratropics in the Northern Hemisphere. Over the Atlantic sector during the positive phase, a cyclonic anomaly-with low geopotential height (Fig. 2e) and a positive vorticity anomaly (Fig. 2g) - is associated with an equatorward shift in the upper-tropospheric jet over the North Atlantic Ocean and eastward extension over Europe (Fig. 2c), along with southerly wind anomalies over western Europe (Fig. 2d). The meridional wind anomalies have a distinct barotropic structure over much of the extratropics but particularly over western Europe where the southerly wind anomaly in the lower troposphere (not shown) closely corresponds to the uppertropospheric wind anomaly. The circumglobal nature of the meridional wind anomalies in the extratropics is reminiscent of the low-frequency teleconnection patterns within the extratropical waveguide during summer (Branstator and Teng 2017). The upper-tropospheric divergence anomaly (Fig. 2h) has highly significant anomalies across much of the equatorial region and closely corresponds to the precipitation anomalies. Over Europe, the first EOF of tropical precipitation is associated with increased precipitation over parts of western Europe and drier conditions over areas of central Europe and Scandinavia. The wet conditions are consistent with the slight southward shift of the climatological jet and the southerly wind anomalies, which act to transport more moisture into western Europe. The dry conditions over central Europe and Scandinavia are associated with dry, northeasterly wind anomalies. The influence on surface air temperatures is less clear over western/central Europe; however, there are significant cool anomalies over eastern Europe (Fig. 2j). These temperature anomalies are largely consistent with the temperature advection due to anomalous southwesterly and northeasterly winds.

The SST anomaly associated with the first EOF of tropical precipitation is shown in Fig. $2 \mathrm{~b}$ and is reminiscent of El Niño SST anomalies over the tropical Pacific. The time series of the first EOF of tropical precipitation and the Niño-3.4 SST indices for the corresponding summer and following winter are shown in Fig. 3. The first EOF of tropical precipitation is strongly correlated with the Niño-3.4 SST anomalies in the tropical Pacific in both the summer $(r=0.91)$ and the following winter $(r=0.88)$ (but not the preceding winter, $r=-0.07)$ and is therefore closely linked to the development of ENSO events. Ding et al. (2011) similarly found that a dominant coupled mode of variability between tropical precipitation and extratropical circulation tended to occur during summers when ENSO was developing. Figure 3 also shows a normalized index of the cyclonic anomaly over the North Atlantic (shown in Fig. 2e), which is significantly related to the first EOF of tropical precipitation $(r=0.49)$. Interestingly, there are also strong circulation anomalies downstream over 
Russia, where positive geopotential height anomalies and persistent blocking highs were important features of the 2010 Russian heatwave (Schneidereit et al. 2012). The 2010 summer was a La Niña year with exceptionally negative value of the tropical precipitation index (Fig. 3), so it is possible that the circulation pattern from the observational analysis, and therefore anomalous tropical precipitation, played a role in the 2010 Russian heat wave. Overall, the observational analysis indicates that the extratropical circulation anomalies associated with the first EOF of tropical precipitation are strongly related to ENSO conditions in the tropical Pacific.

\section{b. Second MCA mode}

The second MCA mode between tropical precipitation anomalies and Z500 over the Euro-Atlantic sector explains $19 \%$ of the squared covariance and the expansion coefficient time series are well correlated $(r=0.75)$. The second eigenvalue is well separated from the following eigenvalues using the rule of thumb of North et al. (1982)_applied to the squared covariance rather than variance following Donges et al. (2015)and therefore warrants consideration. The third MCA mode is not well separated from the fourth so we will not present analysis of these higher modes. Figure 4 shows the regression of anomalous fields on the normalized precipitation time series from the second MCA mode. The precipitation anomalies associated with the second MCA mode are approximately 4-5 times weaker than those for the first EOF mode, with the strongest anomalous precipitation (Fig. 4a) and associated upper-level divergence (Fig. 4h) confined to the eastern tropical Pacific, although the precipitation anomalies also extend to the central tropical Pacific. Nonetheless, there does appear to be significant SLP anomalies in both the eastern and western tropical Pacific (Fig. 4f), indicative of large-scale tropical circulation changes. There are significant SST anomalies associated with the second MCA mode, most notably in the far eastern tropical Pacific, and the second MCA mode is significantly, albeit weakly, anticorrelated with the Niño- $1+2$ index $(r=-0.52)$. The associated extratropical circulation anomalies are generally largest in the Euro-Atlantic sector, which is to be expected given the choice of region for the MCA, and consist of a strengthening of the upper-tropospheric zonal wind in the jet entrance region over the western Atlantic and anomalous anticyclonic circulation farther downstream over Europe (Figs. 4c,e). The anomalous flow over the Euro-Atlantic sector is similar to the first EOF of Z500 (JJA) anomalies in the MCA region-which is sometimes referred to as the summer North Atlantic Oscillation (SNAO)-and the expansion coefficient time series of the $\mathrm{Z} 500$ from the second MCA mode and the first EOF of Z500 are significantly correlated $(r=0.82)$. However, comparison between the circulation anomalies seen in Fig. $4 \mathrm{e}$ and SNAO (i.e., first EOF of Z500) shows that the high over the United Kingdom that is characteristic of the SNAO is located farther east in the second MCA mode. Nonetheless, the tropical precipitation anomalies associated with the second MCA mode do seem to be associated with a preferred phase of the SNAO, albeit the correspondence is not so clear over northern Europe.

\section{c. Storm-track anomalies and feedback}

In comparison with the first EOF of tropical precipitation (i.e., Fig. 2), there are only very weak tropical circulation anomalies associated with the second MCA mode. This suggests that the extratropical circulation anomalies associated with the second MCA mode are related to internal extratropical variability - highlighted by the close correlation with the first EOF of Z500 in the Euro-Atlantic sector-and are less likely to be driven by "direct" teleconnections from tropical precipitation. To examine the relative role of storm-track anomalies in influencing the large-scale circulation anomalies associated with the tropical precipitation variability, we have regressed different storm-track measures onto the first EOF of tropical precipitation and the precipitation time series from the second MCA mode. Figures 5a,b show the meridional eddy heat transport anomaly, $v_{h} T_{h}$ $(850 \mathrm{hPa})$, which is a signature of baroclinic wave growth. The second MCA mode is associated with a significant increase in eddy heat transport over the jet entrance region over the western and northeastern Atlantic, which is consistent with an increased eddy kinetic energy (EKE) in the upper troposphere downstream (Fig. 5d). The eddy heat transport and eddy kinetic energy anomalies associated with the first EOF of tropical precipitation are weaker than those for the second MCA mode anomalies, and constitute an equatorward shift of the storm track over the North Atlantic, consistent with the large-scale changes in the zonal wind.

To assess the extent to which the storm-track anomalies are forcing the large-scale circulation anomalies through eddy feedbacks, we calculated the barotropic energy conversion rate $\mathbf{E} \cdot \mathbf{D}$ (at $250 \mathrm{hPa}$ ). Here $\mathbf{E}=\left[1 / 2\left(u_{h}^{2}-v_{h}^{2}\right),-u_{h} v_{h}\right]$ is similar to the $\mathrm{E}$ vector of Hoskins et al. (1983) and depends on the amplitude and orientation of the high-pass-filtered eddies, and $\mathbf{D}=\left(\partial u_{l} / \partial x-\partial v_{l} / \partial y, \partial v_{l} / \partial x+\partial u_{l} / \partial y\right)$ is a measure of the deformation field of the low-pass-filtered flow. $\mathbf{E} \cdot \mathbf{D}$ is a measure of the rate at which barotropic eddies exchange kinetic energy with the large-scale, 

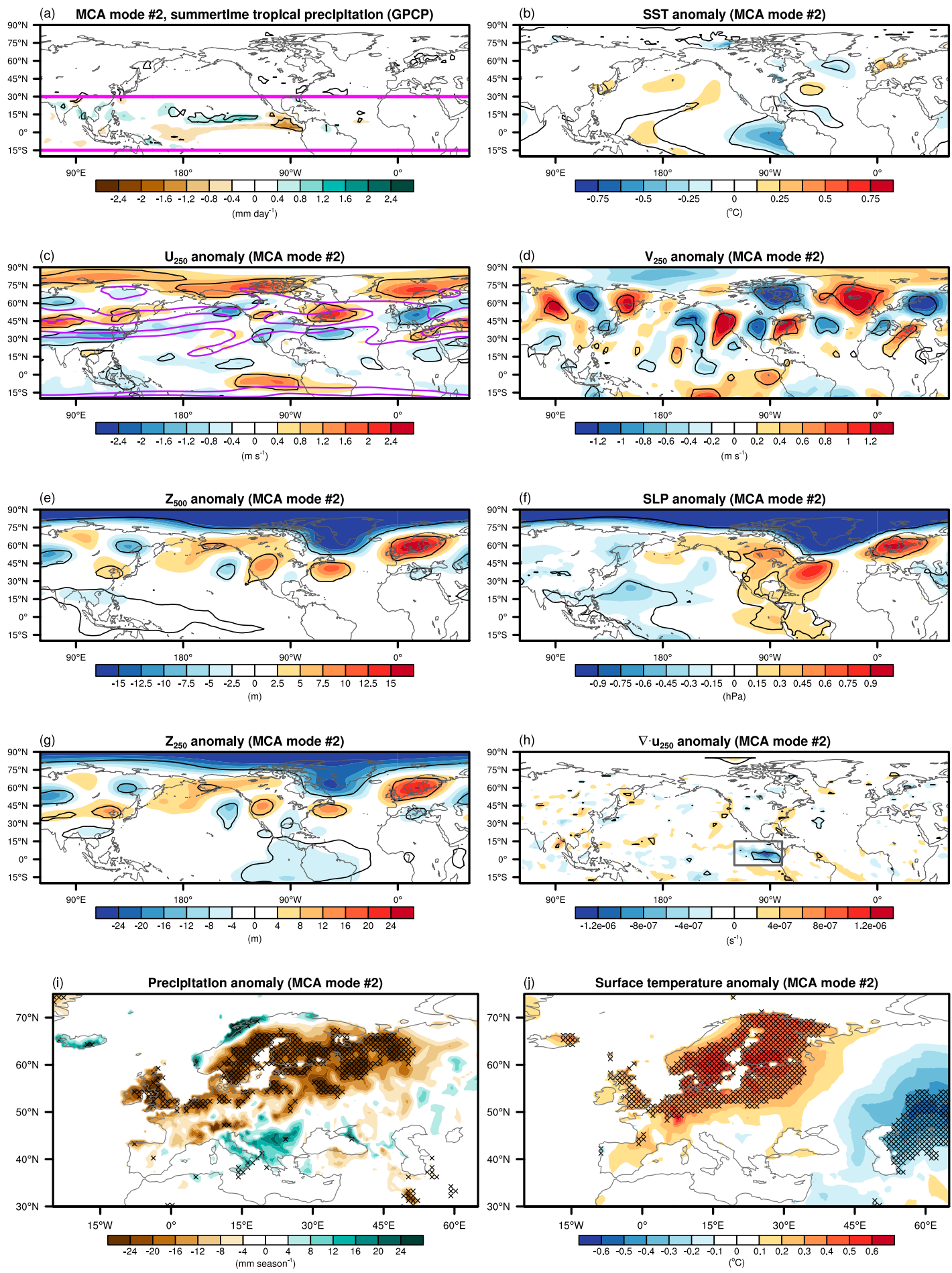

FIG. 4. (a) Anomalous precipitation anomalies, from the GPCP dataset (1979-2016), regressed onto the normalized MCA mode 2 time series (see text for details). Also shown are anomaly fields (linearly detrended) regressed onto the normalized MCA mode 2 time series: (b) SST; (c) $u(250 \mathrm{hPa})$; (d) $v(250 \mathrm{hPa})$; (e) Z500; (f) $v$ (700 hPa); (g) $Z$ $(250 \mathrm{hPa})$; and $(\mathrm{h})$ divergence, $\nabla \cdot \mathbf{u}(250 \mathrm{hPa})$. Also shown are (i) precipitation and (j) surface air temperature anomalies from the CRU-TS gridded dataset (1979-2015) regressed onto the tropical precipitation index. Units are shown per standard deviation of the normalized principal component. The black contours in (b),(c),(d),(e),(f),(g) and stippling in (i),(j) indicate where the anomalies are significant at the $5 \%$ level, using a two-sided $t$ test. The black contours in (a) and (h) indicate where the anomalies are significant at the $1 \%$ level. The region outlined by the gray box in (h) shows the region identified as active tropical precipitation forcing. In (c) the purple contours show the climatological $u(250 \mathrm{hPa})$ at 10 and $20 \mathrm{~m} \mathrm{~s}^{-1}$. The color scales are the same as in Fig. 2, to aid comparison. 

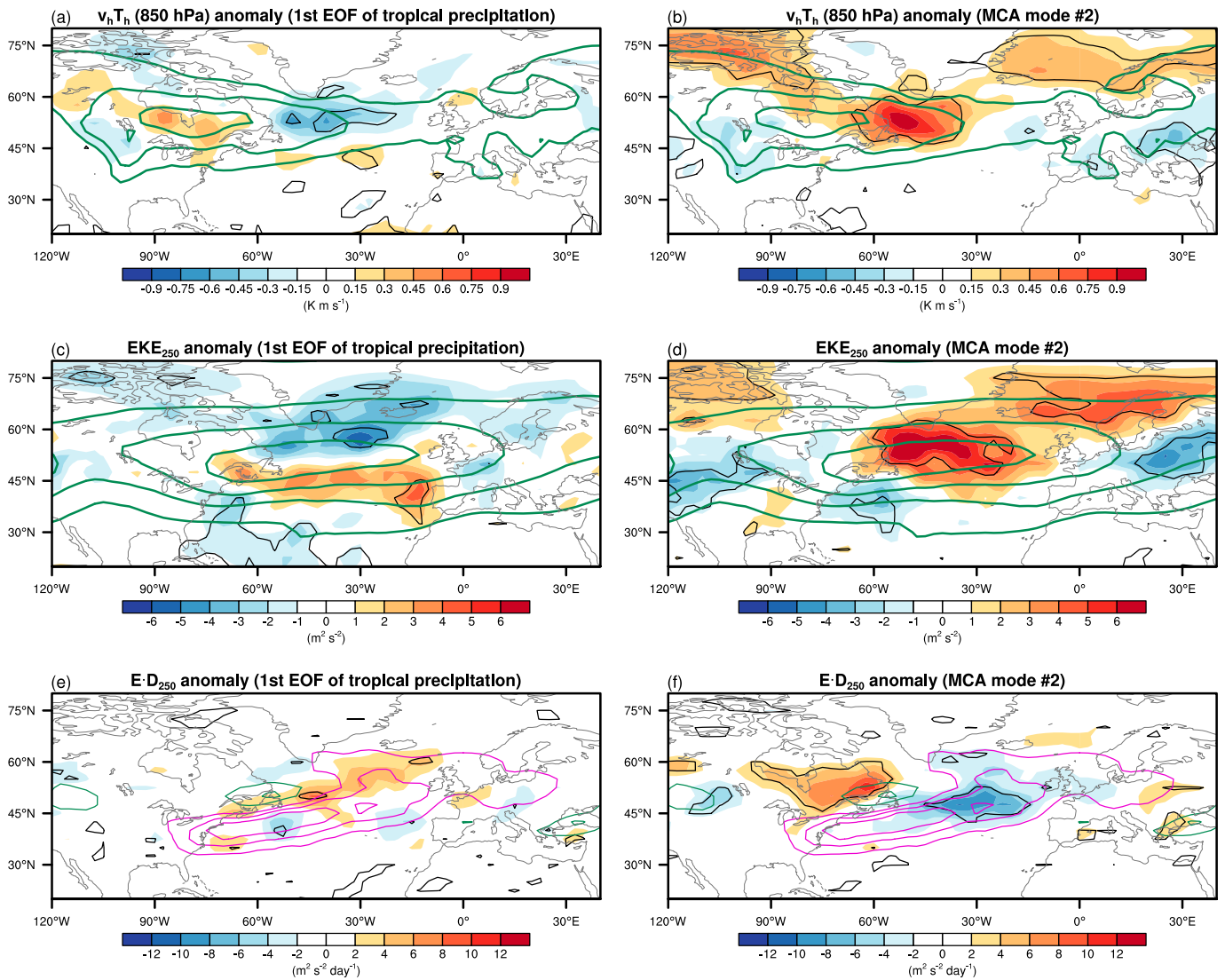

FIG. 5. Summer (JJA) storm-track anomalies regressed onto (a),(c),(e) the tropical precipitation index (i.e., the normalized first principal component time series of tropical precipitation) and (b),(d),(f) the normalized MCA mode 2. (a),(b) Meridional eddy heat transport, $v^{\prime} T^{\prime}(850 \mathrm{hPa})$, anomalies (shading), and climatology (contours, interval $2 \mathrm{~K} \mathrm{~m} \mathrm{~s}^{-1}$, zero contour suppressed). (c),(d) Eddy kinetic energy (EKE), $1 / 2\left(u^{2}+u^{\prime 2}\right)(250 \mathrm{hPa})$, anomalies (shading), and climatology (contours, interval $20 \mathrm{~m}^{2} \mathrm{~s}^{-2}$ ). (e),(f) Eddy-mean flow forcing, $\mathbf{E} \cdot \mathbf{D}(250 \mathrm{hPa})$, anomalies (shading), and climatology (contours, interval $7.5 \mathrm{~m}^{2} \mathrm{~s}^{-2} \mathrm{day}^{-1}$, zero contour suppressed). For the climatologies in all panels, green contours indicate positive values and magenta contours indicate negative values.

lower-frequency circulation (e.g., Mak and Cai 1989; Cai and Mak 1990). There is relatively little significant anomalous eddy feedback associated with the first EOF of tropical precipitation (Fig. 5e). However, the second MCA mode does exhibit significant eddy feedback onto the large-scale circulation (Fig. 5f). In particular, there are significant negative $\mathbf{E} \cdot \mathbf{D}$ anomalies over the North Atlantic associated with the second MCA mode, slightly downstream of the increase in upper-tropospheric eddy kinetic energy. This indicates that the increased eddy kinetic energy is feeding into the large-scale circulation over the eastern North Atlantic, acting to reinforce the circulation anomalies during positive phases of the second MCA mode.

The contrast in eddy forcing of the large-scale circulation anomalies is consistent with the fact that the circulation anomalies are largely confined to the extratropics in the second MCA mode (Fig. 4). One hypothesis is that the relatively weak, albeit significant, precipitation anomalies over the eastern tropical Pacific trigger anomalies that favor one particular phase of the dominant internal mode of variability in the extratropical circulation over the Euro-Atlantic sector. In contrast, the first EOF of tropical precipitation exhibits significant circulation anomalies throughout the tropics (Fig. 2), indicating a more systematic, direct influence of the tropical precipitation anomalies on the extratropical circulation via forcing and propagation of Rossby waves.

\section{Barotropic model results}

\section{a. Response to tropical forcing}

We now investigate the mechanisms by which the observed summer tropical precipitation anomalies can generate circulation anomalies in the extratropics, particularly the equivalent barotropic circulation anomalies over the Euro-Atlantic sector. To do this we employ a 
barotropic vorticity model linearized about a climatological background flow, as described in section 2 . This type of barotropic model has proven to be a useful tool to understand stationary Rossby wave anomalies and propagation in previous studies (e.g., Branstator 1983; Sardeshmukh and Hoskins 1988; Hoskins and Ambrizzi 1993; Ambrizzi et al. 1995; Shaman and Tziperman 2011; Shaman 2014a). The model is linearized about the climatological background flow at $250 \mathrm{hPa}$ and forced by Rossby wave source anomalies in the equatorial regions. The model is forced by anomalous divergence over the region outlined by the gray box in Fig. $2 h$, for the first EOF of tropical precipitation, and in Fig. 4h for the second MCA mode. The divergence anomalies in these regions are highly significant and clearly related to anomalous local precipitation. These divergence anomalies are multiplied by the climatological absolute vorticity field to give an appropriate Rossby wave source forcing. Since these fields have small-scale structure, we produce smooth idealized versions of the Rossby wave source forcing fields with which to suitably force the barotropic model. These idealized forcing structures are produced using a combination of two-dimensional Gaussian functions.

The Rossby wave source field calculated from the divergence anomalies associated with the first EOF of tropical precipitation is shown in Fig. 6a and the idealized version used to force the barotropic model is shown in Fig. 6c. The idealized forcing was chosen to have an amplitude approximately $50 \%$ larger than in the observed anomalies (i.e., Fig. 6a) to give a response of comparable magnitude in the vorticity field (cf. Figs. 6b,d). The stationary response of the barotropic model is shown in Fig. 6d. The response of the model in the tropics is not similar to the circulation anomalies in the observations; this is likely because the tropical circulation changes associated with the precipitation anomalies are baroclinic and not well represented by the barotropic model. Over the Pacific basin there are alternating vorticity anomalies emanating from the tropics. In the extratropical North Pacific the model seems to capture more of the structure seen in the observational field, though it should be noted that there are some appreciable differences (Fig. 6b). Over the EuroAtlantic sector, the model response exhibits some similarities to the observations. In particular, the cyclonic vorticity anomaly west of the British Isles is present in both the model response and the observations, along with successive negative and positive bands of vorticity on the equatorward side. The model also has a band of positive vorticity anomalies over North Africa that extends eastward over the Middle East, which also seems to be present in the observations.
Although the idealized barotropic model does not perfectly reproduce the observations, it seems to be able to capture some of the characteristics of the observed anomalies associated with the first EOF of tropical precipitation. The forcing, however, is large across most of the equatorial regions in the Pacific and Atlantic. To examine which region of the forcing is most important in determining the model response we performed simulations isolating the west Pacific, east Pacific, and Atlantic components of the forcing (Figs. 6e,g,i). The simulation with only the east Pacific forcing component is able to almost completely reproduce the circulation response of the full idealized forcing simulation (Fig. 6f); not only over North America and the North Atlantic but also over Asia. The west Pacific forcing generates a much weaker circulation response, with a slight contribution to the cyclonic circulation anomaly seen over the Atlantic in the extratropics (Fig. 6h). Perhaps surprisingly, the model circulation response to equatorial Atlantic forcing is negligible over the extratropical Atlantic and farther east except over Greenland (Fig. 6j). These simulations suggest that the extratropical anomalies associated with the first EOF of tropical precipitation are most likely generated by divergence anomalies in the eastern equatorial Pacific.

We performed similar barotropic model simulations with equatorial divergent forcing calculated from the second MCA mode (i.e., Figs. $4 \mathrm{~h}$ and $7 \mathrm{c}$ ). The response of the barotropic model to the forcing associated with the second MCA mode is negligible outside of the $\mathrm{Pa}$ cific basin (Fig. 7d) and the observed circulation anomalies over the North Atlantic are not reconcilable with linear barotropic Rossby wave dynamics. This is consistent with our analysis in the previous section, which indicated that eddy-mean flow interaction plays an important role in producing the large-scale circulation anomalies associated with the second MCA mode.

We will now focus further on the response of the barotropic model to the first EOF of tropical precipitation. One interesting aspect of the barotropic model response to the east Pacific forcing (i.e., Fig. 6f) is that there are circulation anomalies of comparable magnitude across much of the midlatitudes. To examine how the Rossby wave response propagates to the EuroAtlantic, we follow the approach of Shaman and Tziperman (2007) and add sponge layers along particular longitudes; these act to damp vorticity anomalies and, therefore, obstruct the zonal group propagation of the Rossby waves. The results of simulations with east Pacific forcing (i.e., Fig. 6e) and sponge layers over Asia $\left(90^{\circ} \mathrm{E}\right)$ and North America $\left(90^{\circ} \mathrm{W}\right)$ are shown in Fig. 8 (note the different color scales for the full and damping simulations). Damping over Asia results in quite a 

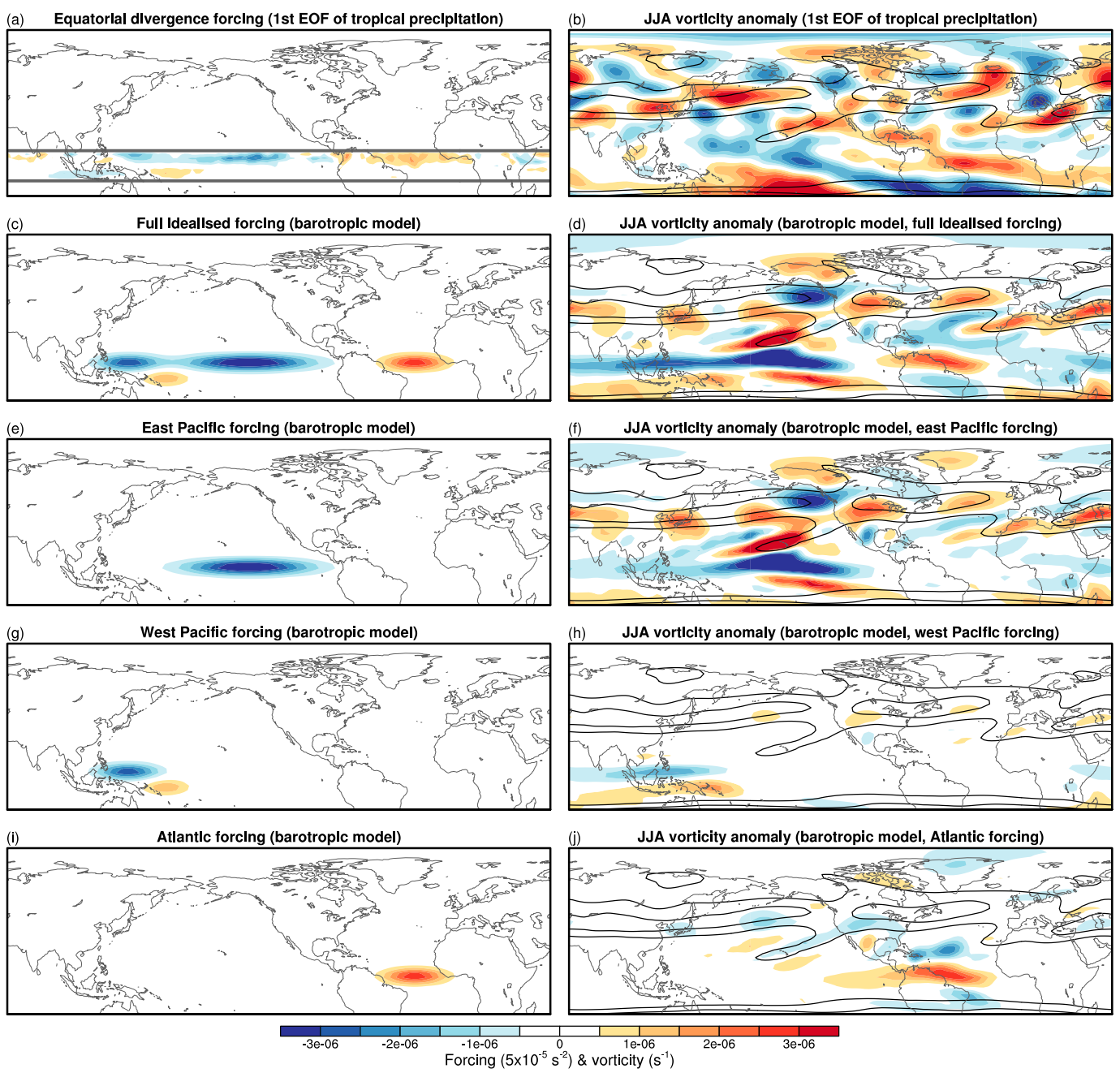

FIG. 6. (a) Observed Rossby wave source anomaly due to anomalous equatorial divergence associated with first EOF of tropical precipitation $\left(15^{\circ} \mathrm{S}-30^{\circ} \mathrm{N}\right.$, shown by the gray lines). (b) Observed relative vorticity anomaly regressed onto the tropical precipitation index. (c),(e),(g),(i) The Rossby wave source forcing for different simulations of the barotropic model for (c) the full idealized forcing, (e) east Pacific forcing, (g) west Pacific forcing, and (i) Atlantic forcing. (d),(f),(h),(k) The relative vorticity anomaly of the linearized barotropic model averaged from day 16-20 for each of the simulations. The black contours show the climatological $u(250 \mathrm{hPa})$ at 10 and $20 \mathrm{~m} \mathrm{~s}^{-1}$. The observed vorticity anomaly in (b) has been smoothed to T21 horizontal resolution to aid comparison with the barotropic model.

different circulation anomaly compared to the simulation without a sponge layer, with the cyclonic anomaly over the North Atlantic becoming displaced eastward over Europe. The simulation with the sponge layer over North America more faithfully reproduces the response of the full model over the North Atlantic, even in the absence of eastward wave energy propagation over North America (Fig. 8c). The simulation with damping over North America reproduces the wave train structure along the Asian jet, indicating that westward Rossby wave group propagation appears crucial in generating the circulation response over the North Atlantic. Shaman (2014a) found similarly superposed eastward- and westward-propagating signals in barotropic model simulations of the late summer (i.e., JAS) response to ENSO-related forcing. In their experiments, as here, the westward-propagating response (via Asia) was found to dominate the eastward-propagating response (via North America), unlike the other seasons during which the response over the North Atlantic to forcing in the tropical Pacific is generated by a northeastwardpropagating wave train. It is important to note that the response of the simulations with damping is approximately half the amplitude of the full experiments, indicating that the circumglobal propagation is important in determining the overall response over the Euro-Atlantic 

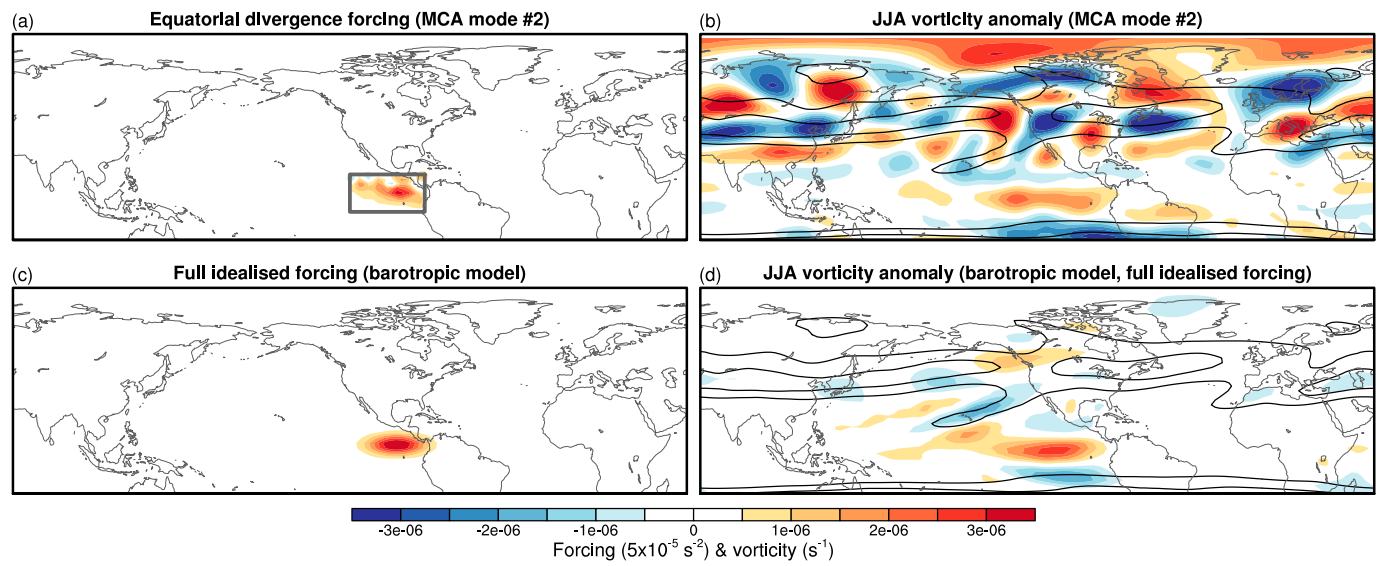

FIG. 7. (a) Observed Rossby wave source anomaly associated with MCA mode 2 (over region outlined by the gray lines, see also Fig. 4h). (b) Observed relative vorticity anomaly regressed onto the tropical precipitation index. (c) The full idealized Rossby wave source forcing. (d) The relative vorticity anomaly of the linearized barotropic model averaged from days 16 to 20 of the simulation. The black contours show the climatological $u(250 \mathrm{hPa})$ at 10 and $20 \mathrm{~m} \mathrm{~s}^{-1}$. The color scales are the same as in Fig. 6, to aid comparison.

sector. One interesting feature of the barotropic simulations is that the positive vorticity anomaly over Japan is larger in the Asia damping simulation than in the North America damping simulation, indicating that the westward-propagating signal tends to build up eastward of the Asian damping region.

To analyze the propagation of the response further we have plotted the transient development of the model response to east Pacific forcing in Fig. 9. The transient development of the full simulation as well as those with Asian and North American damping are shown. The initial response to the forcing in the east Pacific is the poleward propagation of anomalies over the extratropical Pacific. These structures then become elongated and extend westward between days 2 and 6 . As the signal propagates farther westward over Asia, in the full and North American damping simulations, these elongated circulation anomalies split into higher wavenumber components (e.g., the right column in Fig. 9). In the Asian damping simulation, however, the positive vorticity anomaly over Japan becomes larger than in the other simulations at about 6 days when the signal cannot propagate farther west though the damping region. As the response evolves, the cyclonic anomaly that develops over the North Atlantic around day 12 in the full and North American damping simulations extends over Europe prior to becoming a separate anomaly. In the Asian damping experiment an initial anticyclonic anomaly develops over the North Atlantic by about day 8 that then retreats west slightly. Also, it is notable that the cyclonic anomaly over the North Atlantic develops earlier (i.e., day 8) in the North American damping simulation than in the full simulation, whereas the anomaly is stronger in the full simulation by day 16 . The delay in the full simulation appears because of the superposition of the westward-propagating signal and the eastward signal propagating over North America (as in the Asian damping simulation), which is not present in the North American damping simulation. The stronger cyclonic anomaly over the North Atlantic by day 16 in the full simulation, compared with the North American damping simulation, occurs after the circumglobal response pattern is established. This highlights that the circumglobal response is able to amplify more than in the North American damping simulation, potentially through the interaction of the signal propagating across North America with the westward-propagating signal after day 12 .

\section{b. Group velocity of Rossby wave response}

To understand how these signals are able to propagate westward we analyze the barotropic Rossby wave dispersion relation (e.g., Hoskins and Karoly 1981; Karoly 1983; Hoskins and Ambrizzi 1993; Shaman et al. 2009; Shaman and Tziperman 2016). In the presence of a zonally asymmetric background flow, the zonal group velocity $u_{g}$ of stationary Rossby waves for the Mercator projection on a sphere is given by

$$
u_{g}=\bar{u}_{M}+\frac{\left(k^{2}-l^{2}\right) \beta_{M}-2 k l \partial \bar{\zeta} / \partial x}{\left(k^{2}+l^{2}\right)^{2}}
$$

where $\bar{u}_{M}=\bar{u} / \cos \theta ; \beta_{M}=\partial \bar{\zeta} / \partial y$ is the meridional gradient of absolute vorticity; and $k$ and $l$ are the zonal and meridional wavenumbers, respectively. As highlighted in Hoskins and Ambrizzi (1993), in the limit of 

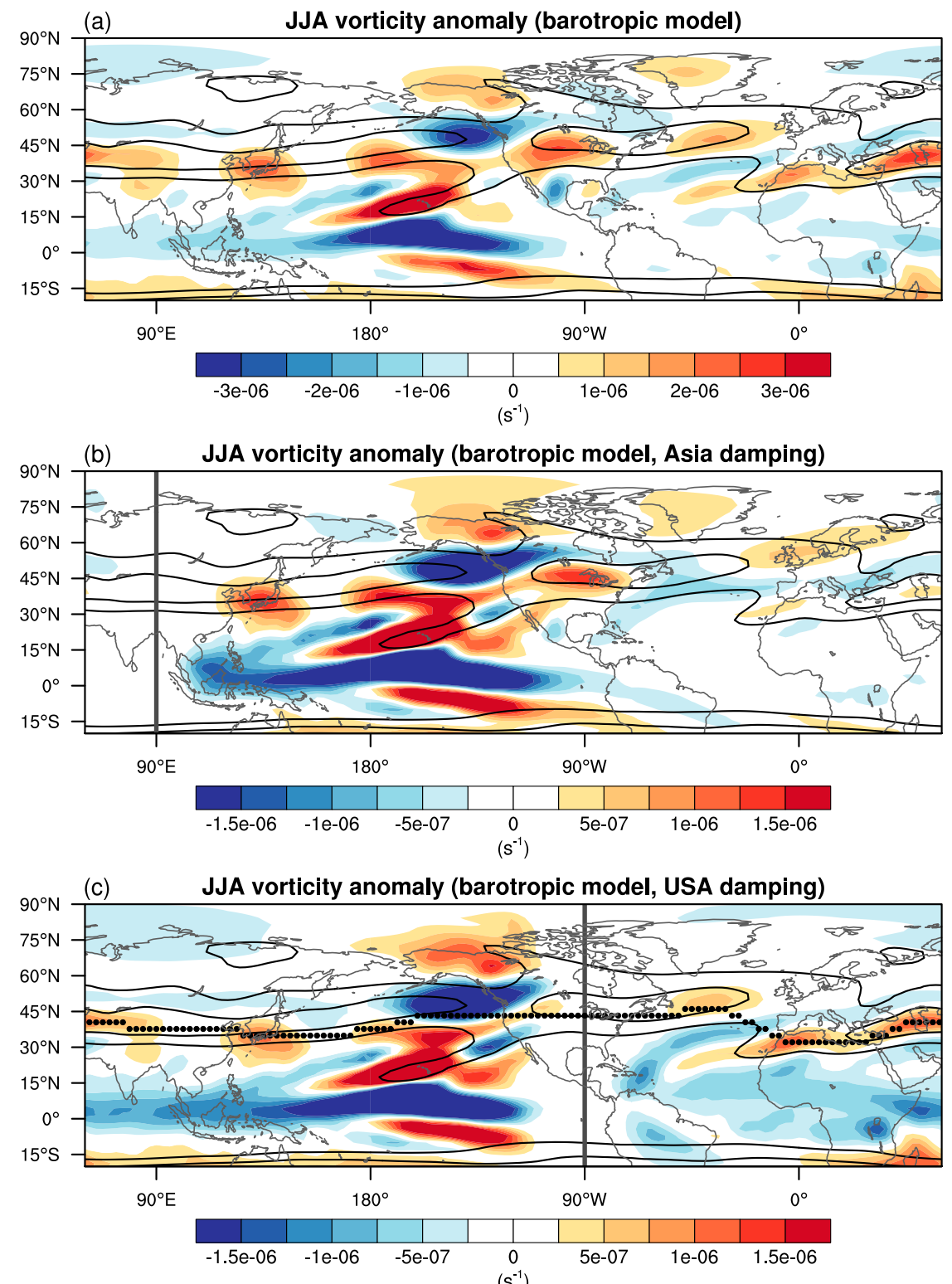

FIG. 8. The relative vorticity anomaly averaged between days 16 and 20 for simulations with (a) no damping, (b) damping over Asia $\left(90^{\circ} \mathrm{E}\right)$, and (c) damping over the United States $\left(90^{\circ} \mathrm{W}\right)$. The black contours show the climatological $u(250 \mathrm{hPa})$ at 10 and $20 \mathrm{~m} \mathrm{~s}^{-1}$. The sponge layers are shown by the thick gray lines in (b) and (c). Each simulation was performed with east Pacific idealized forcing (as shown in Fig. 6e). The dotted line in (a) shows the latitude of the waveguide used to plot the Hovmöller diagrams in Fig. 11. Note that the color scales for the damping simulations in (b) and (c) are half the magnitude of the scale in (a).

elongated zonal waves, where $k^{2} \ll l^{2}$, the zonal group velocity approaches

$$
u_{g}=\bar{u}_{M}-\frac{\beta_{M}}{l^{2}} .
$$

This means that long zonal Rossby waves, with a limited meridional extent, can have westward group velocity in regions with a sharp positive meridional vorticity gradient. In barotropic simulations linearized about the Northern Hemisphere winter circulation, Hoskins and Ambrizzi (1993) observed westward propagation when forcing was applied in a region of strong positive meridional vorticity gradient (their Fig. 11). Summer climatological fields of $u_{M}, \beta_{M}$, and $u_{g}$ in the $k^{2} \ll l^{2}$ limit (for meridional half-wavelength $\pi / l=3.5 \times 10^{6} \mathrm{~m}$ ) are shown in Fig. 10. The map of $u_{g}$ (in the limit of zonally 

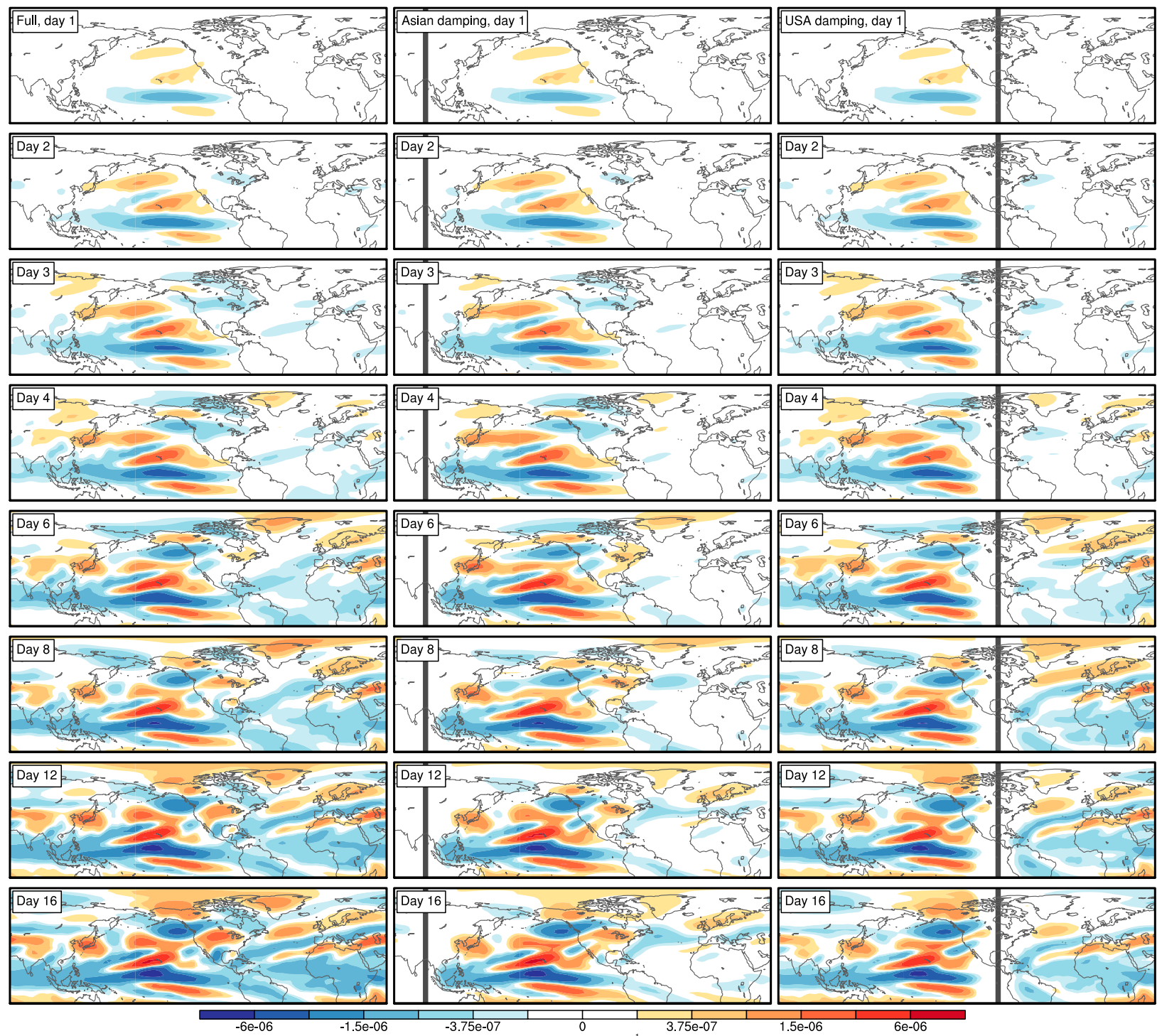

FIG. 9. The transient response of the barotropic model experiments shown in Fig. 8, with (left) no damping, (middle) Asian damping, and (right) U.S. damping. Each simulation was performed with east Pacific idealized forcing (as shown in Fig. 6e). Note that a nonlinear color scale has been used here to aid comparison.

elongated waves) reveals negative group velocities across the tropics, where the background flow is easterly, but also along the southern flank of the Asian jet, where the positive meridional vorticity gradient is strongest. This explains why in the model simulations zonally elongated Rossby waves are seen extending toward Europe along the southern flank of the Asian jet in the barotropic model simulations (i.e., Figs. 6 and 9).

Rossby waves that do not satisfy the long-wave limit, however, are still expected to have eastward group propagation. Therefore, the smaller-scale features that develop following the elongated waves could be due to shorter eastward-propagating Rossby waves, seemingly triggered following the arrival of westward-propagating waves. To allow us to analyze the development of the circulation response, Hovmöller plots of the circulation anomaly in the North America damping simulation, along the approximate latitude of the "quasi-zonal" waveguide (see Fig. 8c), are shown in Fig. 11. This approximate waveguide was selected following the latitude of the largest vorticity anomalies that are confined to the region of strong zonal flow but also minimizing the variation in latitude. The phase evolution of the vorticity anomaly is reasonably stationary in time. Both westward and eastward group propagation along the waveguide from the forcing region (around $200^{\circ} \mathrm{E}$ ) is also apparent. 

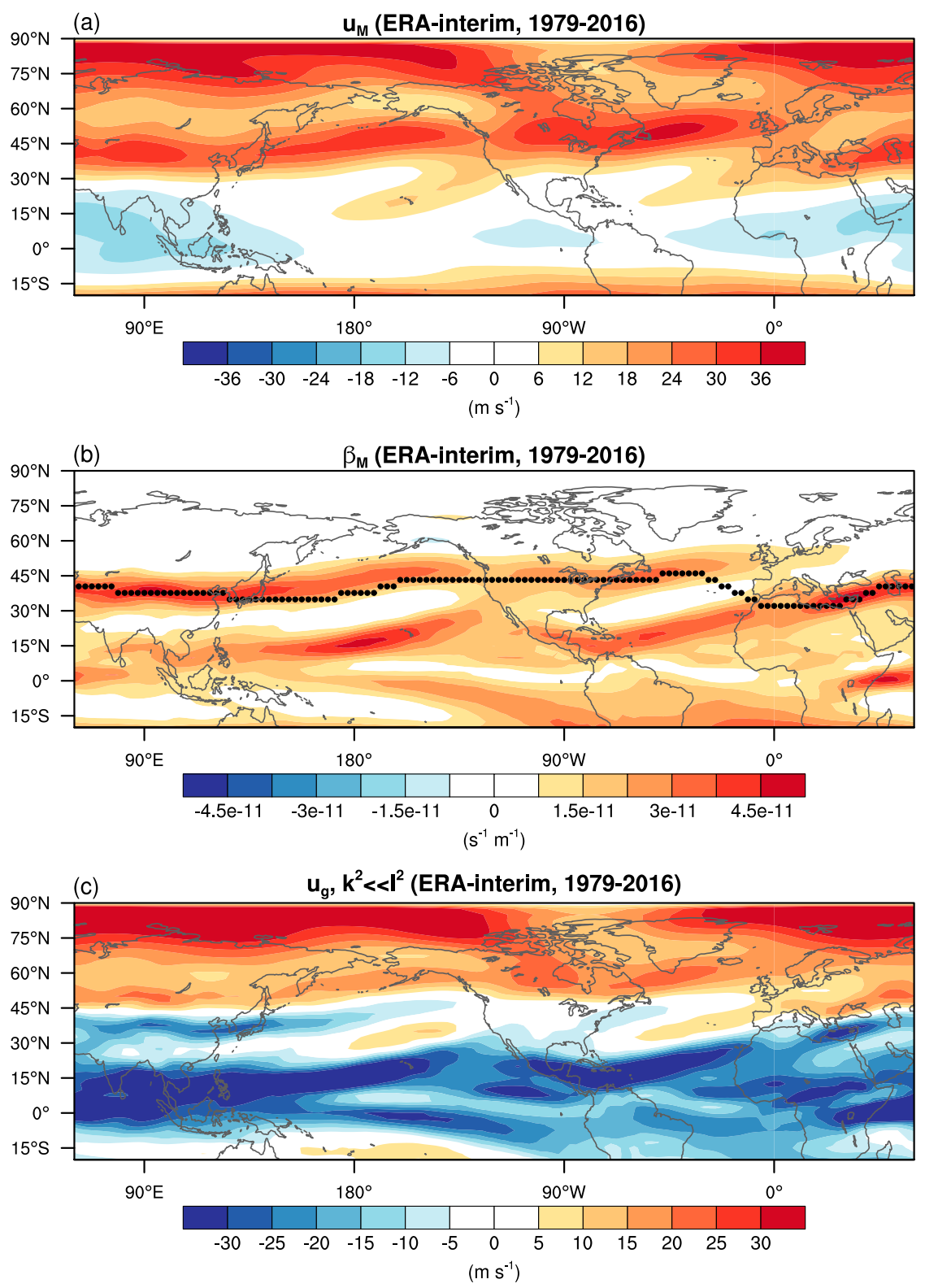

FIG. 10. (a) The climatological Mercator zonal velocity $u_{M}$ at the 250 -hPa level. (b) The climatological meridional gradient of absolute vorticity $\beta_{M}$ at the 250 -hPa level. (c) The zonal group velocity $u_{g}$ at the 250 -hPa level in the long-wave limit (i.e., $k^{2} \ll l^{2}$ ). All plots are for the boreal summer (JJA). The dotted line in (a) shows the latitude of the waveguide used to plot the Hovmöller diagrams in Fig. 11.

However, the circulation anomalies exhibit clear shortwave structure, which is not consistent with the theory of westward-propagating long zonal waves. To separate the shorter waves and the longer waves we performed a simple Fourier decomposition on the circulation anomalies along the waveguide. The Hovmöller plot of the long-wave $(k \leq 3)$ response clearly shows the westward group propagation of the stationary Rossby wave response toward Europe (Fig. 11b). The short-wave $(k>3)$ response, however, shows no clear westward group propagation (Fig. 11c). The short-wave anomalies that develop over the west Pacific (i.e., $120^{\circ}-150^{\circ} \mathrm{E}$ ) follow the arrival of the long-wave response, and then there is eastward group propagation toward North America. The short-wave anomalies that develop over Europe at around day 6 appear, at first glance, to have propagated westward but they follow the arrival of the stronger long-wave anomaly a day or two earlier. Our 

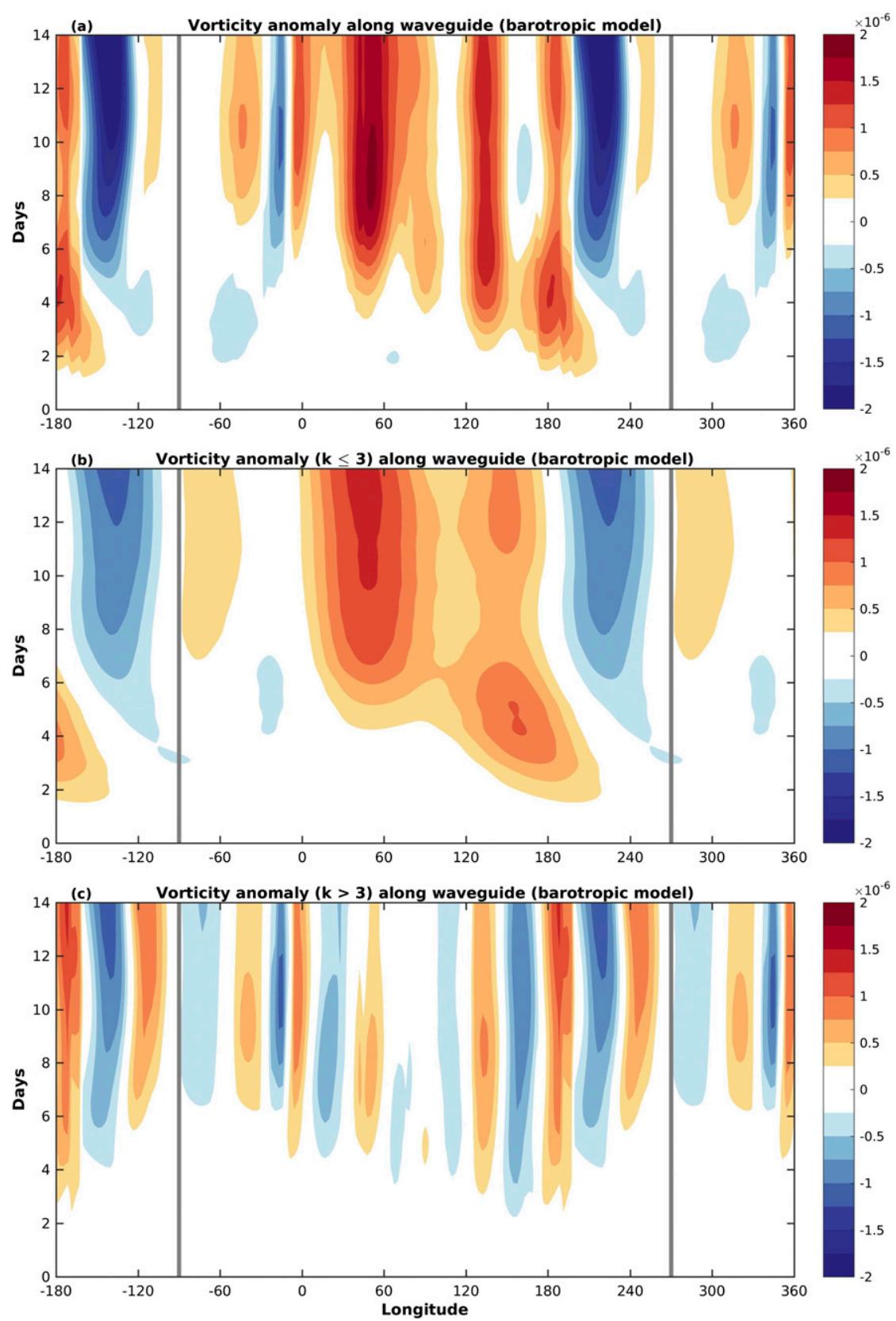

FIG. 11. Hovmöller plot of the response along the extratropical waveguide (shown in Fig. 8c) for the east Pacific forcing simulation with damping over North America (i.e., Fig. 8c) for (a) the relative vorticity anomaly; (b) as in (a), but for the long waves $(k \leq 3)$; and (c) as in (a); but for the short waves $(k>3)$. The vertical gray lines indicate the position of the sponge layer damping in the simulation. Note that the $x$ axis loops around $480^{\circ}$ in longitude.

interpretation is that the short-wave structure in the full circulation response (i.e., Fig. 11) is the result of shorter waves that are triggered in response to the arrival of westward-propagating long waves. This can also be seen in the maps of the transient circulation response (i.e., Fig. 9).

\section{Tropical precipitation variability and associated extratropical circulation in a seasonal forecast model}

We now analyze the summer precipitation variability and associated circulation anomalies in an operational 

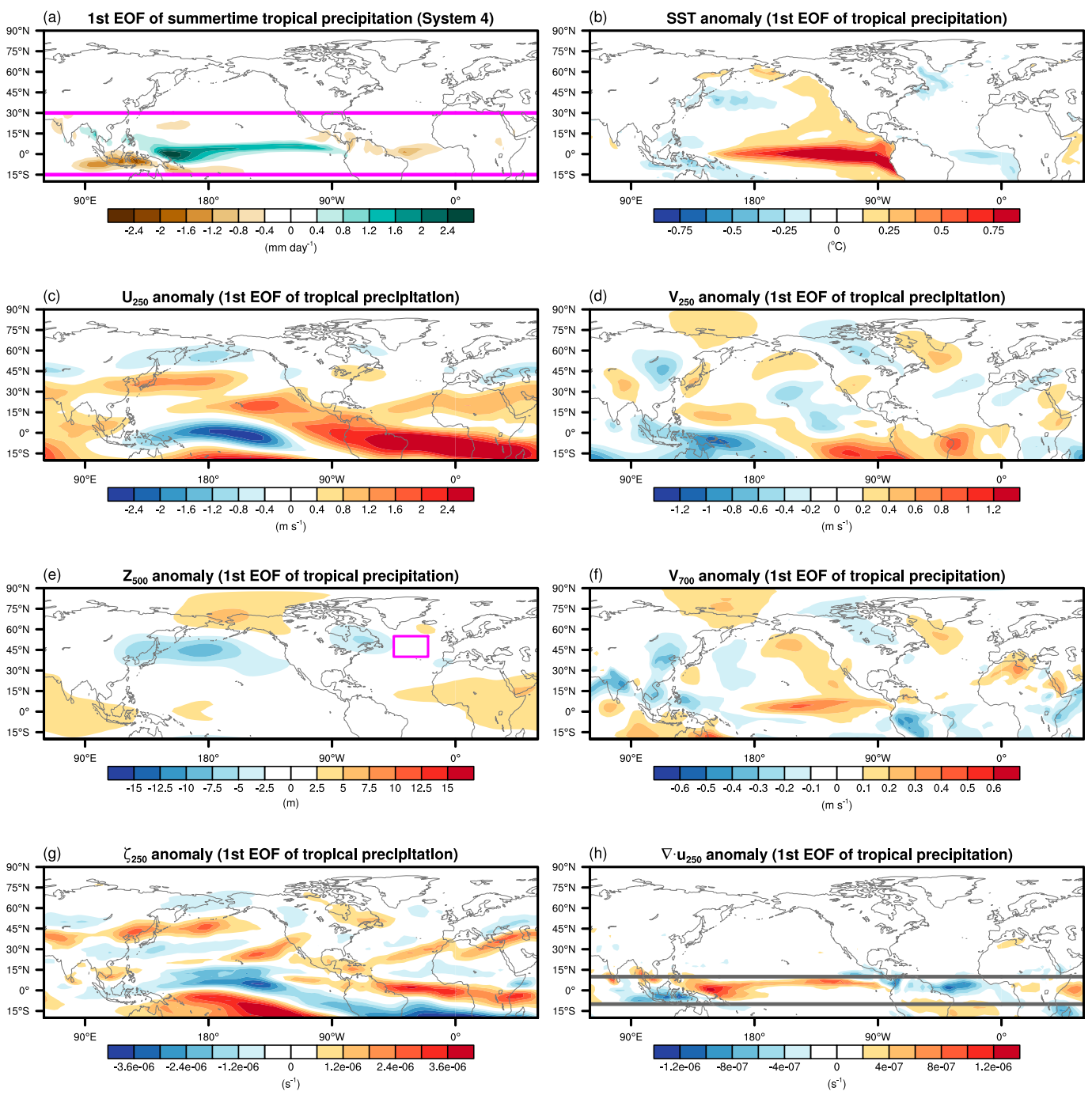

FIG. 12. (a) The first EOF of boreal summer (i.e., JJA) anomalous precipitation anomalies over the tropics (defined as $15^{\circ} \mathrm{S}-30^{\circ} \mathrm{N}$, shown by the magenta lines) from all 51 ensemble members from the ECMWF System 4 seasonal forecasts (1981-2014). Also shown are anomaly fields regressed onto the normalized first principal component time series of tropical precipitation: (b) SST; (c) $u(250 \mathrm{hPa})$; (d) $v(250 \mathrm{hPa})$; (e) Z500; (f) $v$ (700 hPa); $(\mathrm{g})$ relative vorticity, $\zeta(250 \mathrm{hPa})$; and $(\mathrm{h})$ divergence, $\nabla \cdot \mathbf{u}(250 \mathrm{hPa})$. All shaded regions are significant at the $1 \%$ level according to a two-sided $t$ test. The color scales are the same as in Fig. 2, to aid comparison.

seasonal forecast model. Since the tropical precipitation appears to be associated with significant circulation anomalies over much of the extratropics, largely consistent with a simple barotropic Rossby wave response, it is of interest to assess how this is represented in operational seasonal forecast models. Tropical precipitation is typically skillfully forecast in seasonal forecast models and is a key source of skill during forecasts of the winter season (e.g., Smith et al. 2012; Scaife et al. 2017). Here we analyze the ECMWF seasonal forecasting system 4 (hereafter "System 4"; Molteni et al. 2011), for summer (JJA) seasonal forecasts, consisting of 51 ensemble members initialized on
1 May each year. We combine data over the reforecast period, between 1981 and 2010, and additional years from the operational forecast output, between 2011 and 2014, to produce the 34-yr dataset analyzed here.

To compare the tropical precipitation variability in the System 4 to the observations we calculate the first EOF of JJA tropical precipitation. The first EOF is calculated over all ensemble members and years (i.e., $N=51 \times 34=1734$ seasons) and the regression of other variables on the normalized first principal component index are shown in Fig. 12. The precipitation pattern closely resembles the first EOF in observations (Fig. 12a), as does the anomalous upper-level 

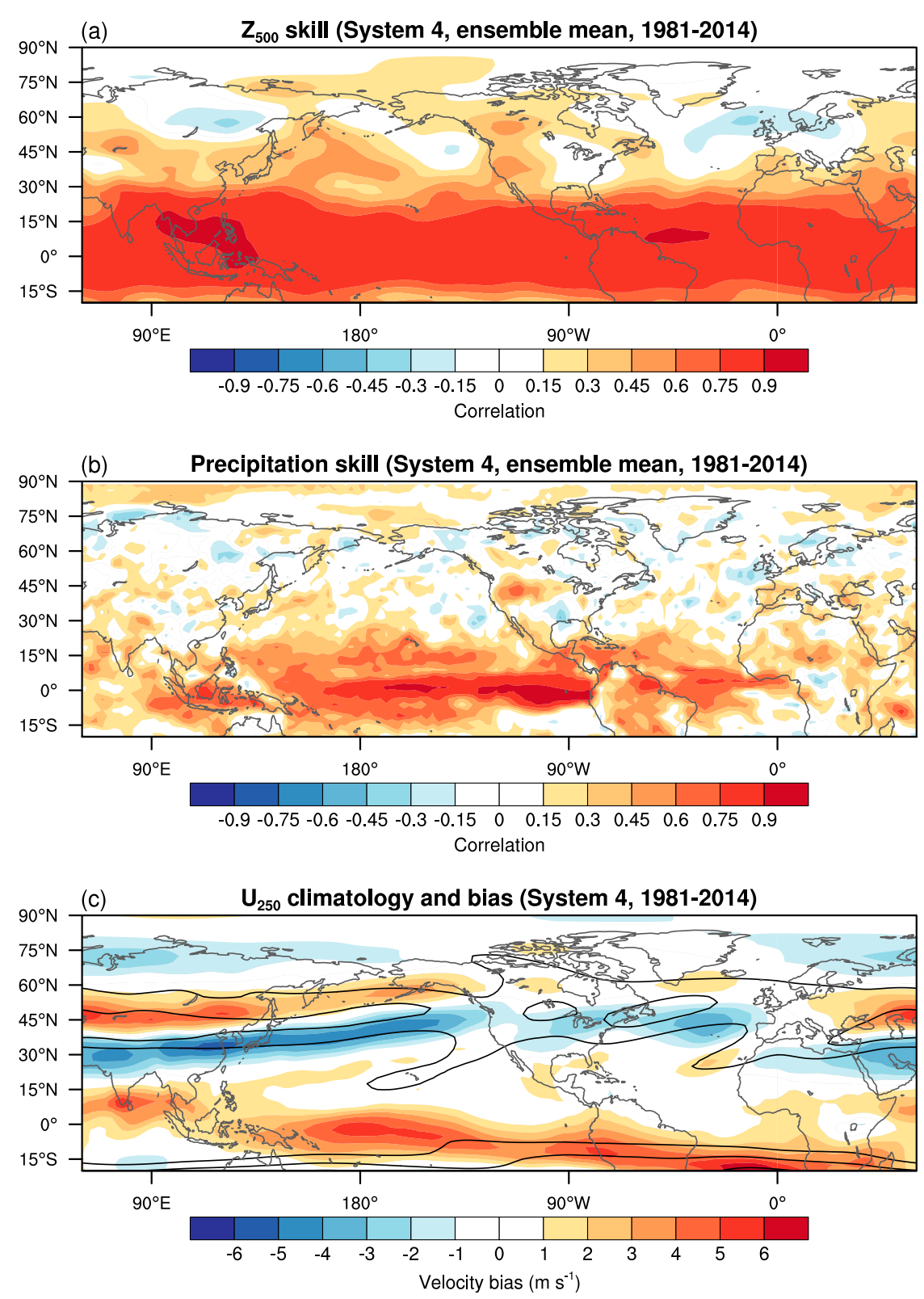

FIG. 13. Ensemble mean hindcast skill for the summer (a) Z500 anomalies and (b) precipitation anomalies in the System-4 hindcasts (1981-2014). (c) The climatology (in contours) and bias (in shading) of $u(250 \mathrm{hPa})$ in the System- 4 hindcasts. The bias is shown with respect to the ERA-Interim climatology over the same period.

divergence associated with the precipitation (Fig. 12h). The associated extratropical circulation anomalies over the Pacific basin are also reasonably well reproduced by System 4. In particular, the cyclonic anomaly over the midlatitude Pacific Ocean and the equatorward shift of the upper-level jet in the observations is also present in System 4, albeit somewhat displaced and weaker than in observations. Over the Euro-Atlantic sector, however, the circulation anomalies seen in the observations are not well captured in System 4, with only the band of cyclonic vorticity over the subtropical North Atlantic and the band of cyclonic anomaly over the Middle East being comparable.

The ensemble mean skill of Z500 and precipitation in System 4 are shown in Fig. 13. The inability of System 4 to replicate the teleconnection from the tropical Pacific precipitation to the Euro-Atlantic sector likely contributes to the lack of skill in seasonal forecasts of summertime circulation in this region (e.g., Z500; Fig. 13a). However, the tropical precipitation is very 
skillfully forecast by System 4 (Fig. 13b). Projecting the forecast precipitation anomalies onto the first EOF of observed tropical precipitation (i.e., Fig. 2a) and correlating this time series with that of the observed leading EOF yields a forecast skill of $r=0.90$ for the first principal component time series. Given that the first EOF of tropical precipitation is very skillfully forecast, it seems that the signal is not propagating into the Euro-Atlantic sector in the same manner as in the observations and the barotropic model. One potential reason for this could be that the model has a different climatological circulation, thereby influencing the teleconnections. The bias of $u$ $(250 \mathrm{hPa})$ in System 4 is shown in Fig. 12c. There is a clear poleward bias along the Pacific and Asian jet stream; this is also present to a lesser extent in the Atlantic, where the jet is somewhat too weak over the jet exit region.

To test the extent to which the biases in the jet stream are influencing the stationary Rossby wave response to tropical heating, we performed additional simulations with the barotropic model, linearized about the System 4 climatological circulation. The circulation response to east Pacific forcing (i.e., Fig. 6e) is shown in Fig. 14a. Barotropic model simulations with sponge layer damping over Asia and over North America, as in Fig. 8, were also performed (Figs. 14b,c). The barotropic model captures some of the characteristics of circulation anomalies in System 4 associated with the first EOF of tropical precipitation, in particular the circumglobal nature of the teleconnection, although the response in the full model is perhaps displaced slightly poleward in comparison to the barotropic model (i.e., Fig. 12g). The response of the barotropic model is generally similar to the simulation using the ERA-Interim background state; however, the series of positive vorticity anomalies moving along the Pacific and Asian jet are somewhat weaker (Fig. 8a). This is likely a result of the poleward jet bias in System 4, which causes tropical forcing to generate Rossby wave anomalies less efficiently. This is shown quite clearly in a barotropic simulation with the System 4 background state performed with sponge layer damping over North America, shown in Fig. 14c. The circulation response along the Asian/west Pacific jet stream is substantially weaker than in the equivalent experiment with the ERA-Interim background state (i.e., Fig. 8c). Therefore, the westward Rossby wave propagation that seems to be an important component of the response to precipitation in the tropical Pacific may not be well captured in System 4 because of the substantial climatological Asian/west Pacific jet biases.

Projecting the forecast precipitation anomalies onto the second MCA mode from the observations (i.e., Fig. 4a) yields a skillful ensemble mean forecast
( $r=0.75)$ for the second MCA mode index. However, the regression of circulation anomalies on the second MCA mode projected index (from System 4) do not show any clear correspondence to the anomalies of MCA mode 2 in the observations (not shown). Therefore, the apparent interaction between the tropical precipitation anomalies and the storm track involved in the second MCA mode is not well reproduced in the model.

\section{Summary and further discussion}

In this study we have investigated the influence of summertime tropical precipitation variability on seasonal circulation anomalies in the Euro-Atlantic sector. The MCA using observational data revealed a dominant mode of covariability between tropical precipitation and Z500 in the Euro-Atlantic sector that was indistinguishable from the first EOF of tropical precipitation. The Euro-Atlantic circulation anomalies associated with the first EOF of tropical precipitation (in the positive phase) consists of a cyclonic anomaly over the extratropical North Atlantic and is associated with summertime climate anomalies over Eurasia (Fig. 2). The first EOF of tropical precipitation is related to tropical Pacific SST anomalies and is closely linked to ENSO (Fig. 3).

The barotropic model simulations indicate that the observed link between the first EOF of tropical precipitation and the Euro-Atlantic circulation anomalies are largely consistent with linear Rossby wave dynamics. The model response was seen to be primarily forced by divergence anomalies in the eastern tropical Pacific (Fig. 6) and the westward group propagation of the Rossby waves was found to be crucial in determining the circulation response over the Euro-Atlantic sector (Figs. 8 and 9). The westward group propagation of zonally elongated Rossby waves is superposed with shorter waves that propagate with eastward group velocity and give rise to the small-scale structure in the total response (Fig. 11). However, the barotropic model response is significantly larger without sponge layer damping over North America. This suggests that the circumglobal nature of the extratropical circulation response-also apparent in the observational analysis (Fig. 2)-reflects the importance of both eastward and westward wave propagation in determining the full response to tropical forcing.

The response of the barotropic simulations is similar to that found by Shaman (2014a) for the late summer season (i.e., JAS). However, Shaman (2014a) note that the observed circulation anomaly associated with ENSO in this season has the opposite sign over the North 


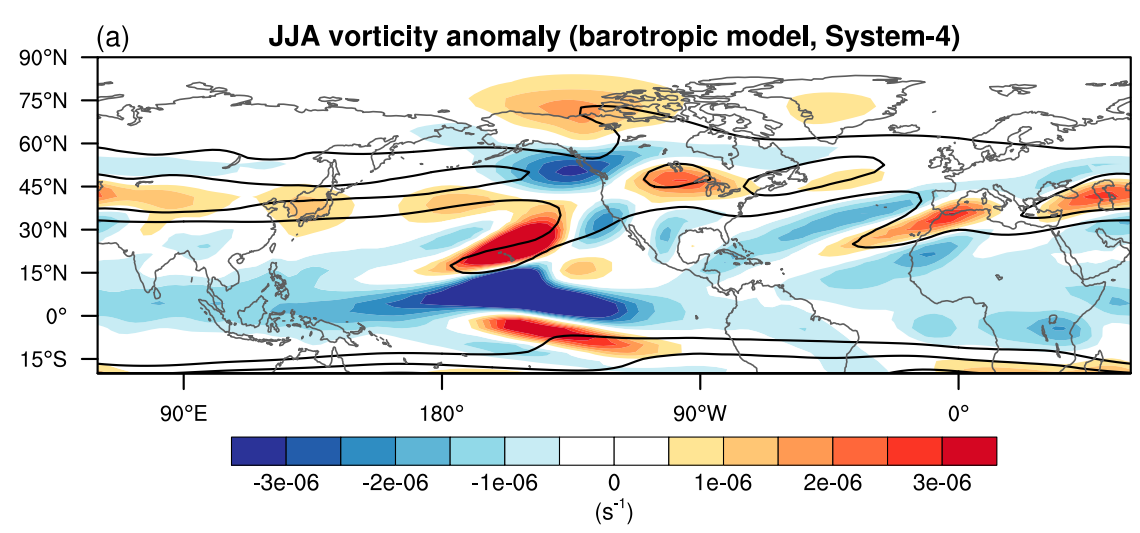

(b) JJA vorticity anomaly (barotropic model, System-4, Asia damping)
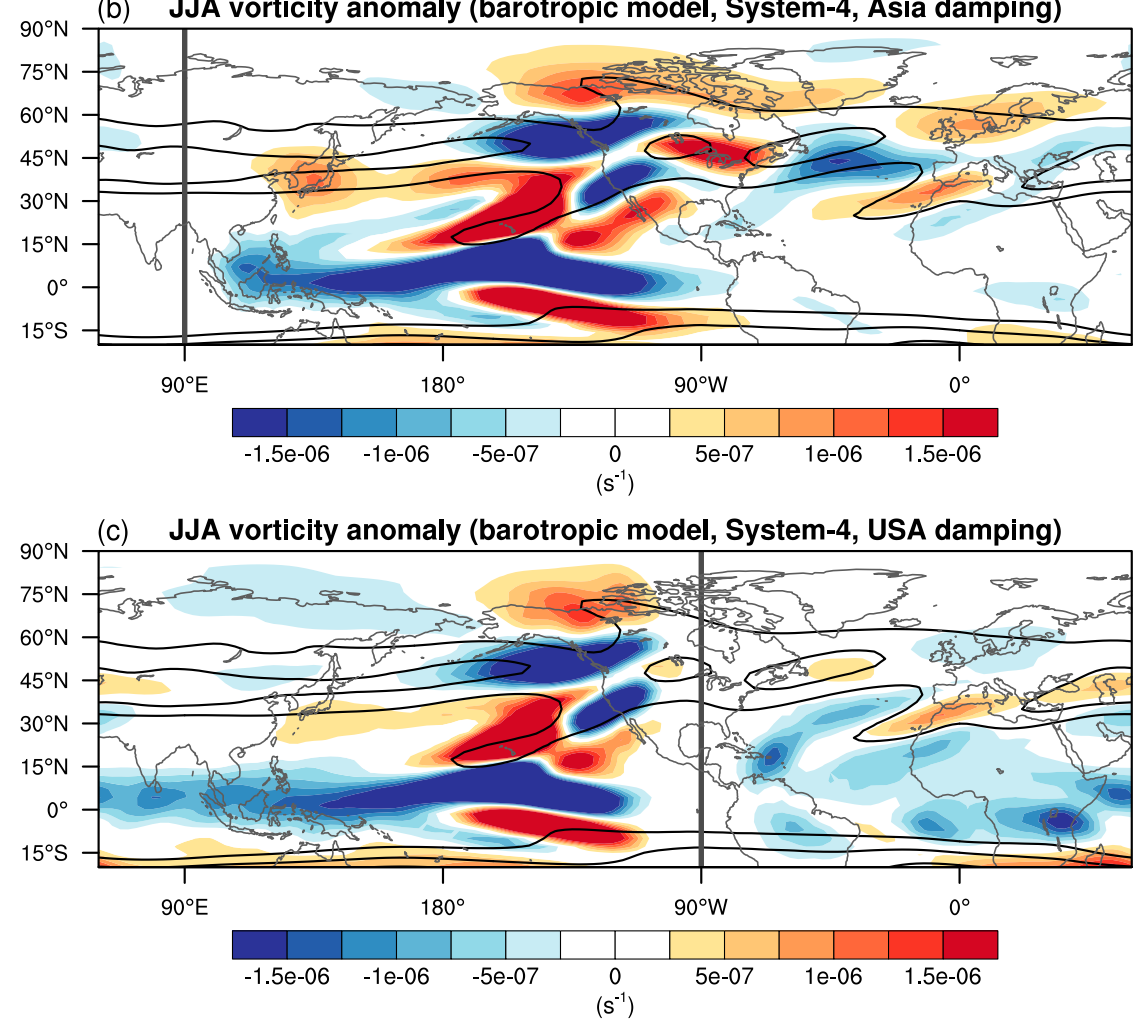

FIG. 14. The linearized barotropic model results, as in Fig. 8, but here linearized around the System-4 climatological winds at the 250 -hPa level. The relative vorticity anomaly averaged between days 16 and 20 for simulations with (a) no damping, (b) damping over Asia $\left(90^{\circ} \mathrm{E}\right)$, and (c) damping over the United States $\left(90^{\circ} \mathrm{W}\right)$. The black contours show the System- 4 climatological $u(250 \mathrm{hPa})$ at 10 and $20 \mathrm{~m} \mathrm{~s}^{-1}$. The sponge layers are shown by the thick gray lines in (b) and (c). Each simulation was performed with east Pacific idealized forcing (as shown in Fig. $6 \mathrm{~g}$ ).

Atlantic. As well as the different summer season definition, the apparent disparity could be due to Shaman (2014a) analyzing the observed circulation response to tropical SST indices whereas here we use observed precipitation anomalies. The precipitation is a proxy for latent heating of the atmosphere, while tropical SST anomalies represent the potential for anomalous heating. For example, the Niño-3.4 index accounts for $80 \%$ of the variance in the first EOF of tropical precipitation. Another potentially important difference between the results of this paper and the findings of Shaman (2014a) is that the latter are based on a different period, 19492011. It could be that the response to tropical Pacific forcing is not stationary, which seems to be the case for winter teleconnections (e.g., Greatbatch and Jung 2007; Brands 2017; O'Reilly et al. 2017a; O'Reilly 2018). 

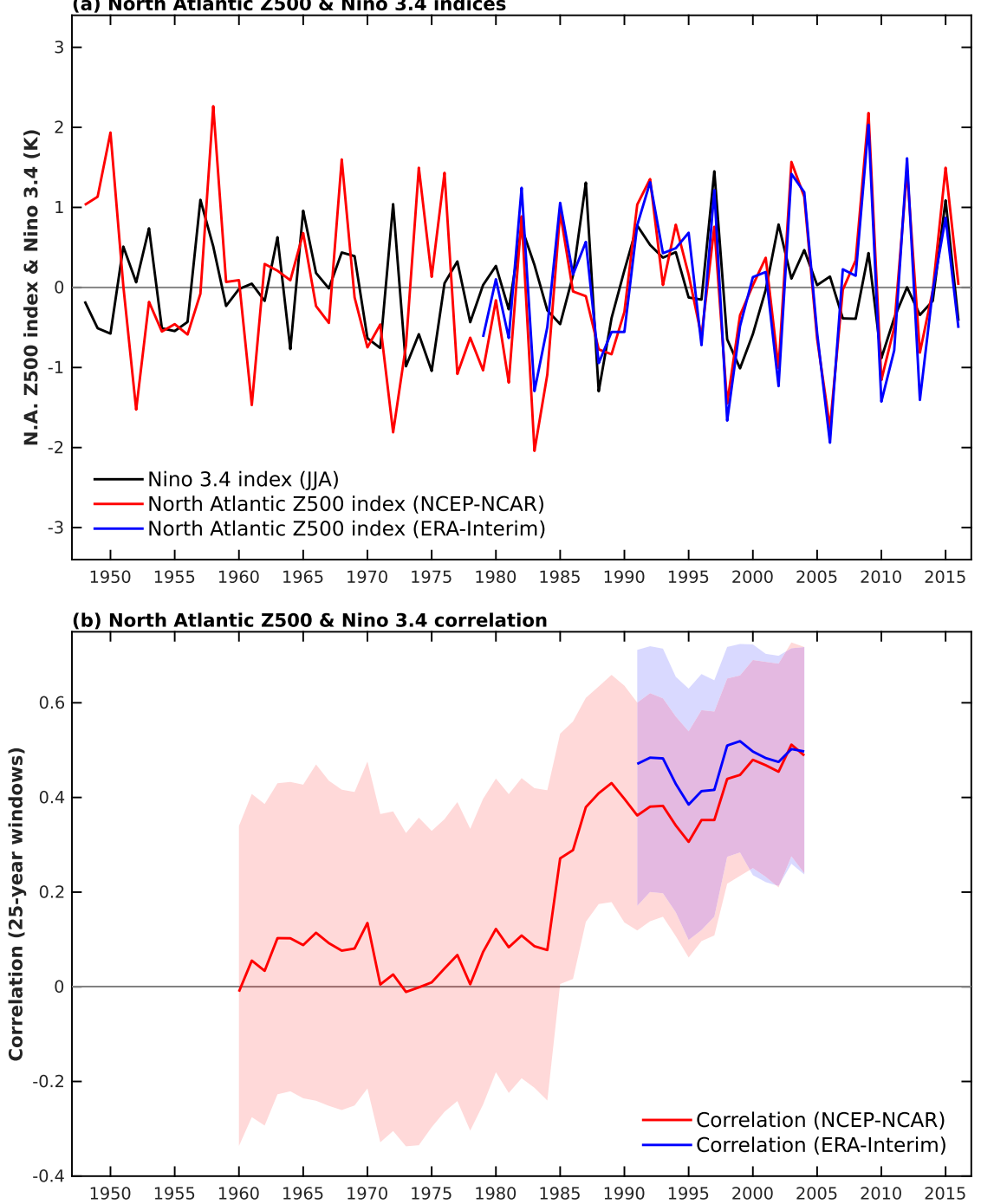

FIG. 15. (a) Niño-3.4 (JJA) index and normalized North Atlantic Z500 indices from ERAInterim (1979-2016, as in Fig. 3) and from NCEP-NCAR reanalysis (1948-2016). The Z500 indices are averaged over the region outlined in Fig. $2 \mathrm{e}\left(40^{\circ}-55^{\circ} \mathrm{N}, 45^{\circ}-20^{\circ} \mathrm{W}\right)$ and multiplied by -1 . (b) Correlation between the Z500 indices and the Niño-3.4 index in moving 25-yr windows. The shading indicates the $5 \%-95 \%$ confidence interval calculated using a bootstrapping with replacement method performed 10000 times.

To assess the importance of the analysis period on the teleconnection from the tropical Pacific to the EuroAtlantic sector we analyze the Niño-3.4 index and North Atlantic Z500 index from 1948 to 2016, using the NCEP-NCAR reanalysis (Fig. 15a). The correlation between the two indices over moving 25 -yr periods is shown in Fig. 15b. The strong relationship between Niño-3.4 tropical Pacific SSTs and the Euro-Atlantic circulation weakens dramatically before the ERAInterim period (1979-2016, also shown in Fig. 15b) and is essentially zero during the period between 1948 and 1978. This indicates that the apparent disagreement between the observational analysis shown here and the results of Shaman (2014a) is mostly due to the different periods analyzed. The dramatic shift in the relationship between Niño-3.4 tropical Pacific SSTs and the EuroAtlantic circulation in the late-1970s does not seem to be associated with the magnitude of tropical Pacific forcing, which has approximately equal variance in the earlier period $\left(0.36 \mathrm{~K}^{2}, 1948-78\right)$ and the later period $\left(0.37 \mathrm{~K}^{2}\right.$, 1979-2016). However, since we do not have satellite data for the earlier period, we cannot verify whether the precipitation anomalies associated with the Niño-3.4 tropical Pacific SSTs were similar to those observed over 
the later period. The varying link between the tropical Pacific and Euro-Atlantic circulation clearly warrants further study and is something we are actively investigating.

We also analyzed the second MCA mode, which was found to consist of weaker precipitation anomalies than the first EOF of tropical precipitation, located in the eastern tropical Pacific, but these are associated with much stronger associated circulation over the EuroAtlantic sector (Fig. 4). Analysis of the storm-track anomalies and eddy-mean flow interaction (Fig. 5) suggest that the large-scale circulation anomalies associated with the second MCA mode-which closely corresponds to the first EOF of Z500 in the Euro-Atlantic sector-are predominantly the result of internal atmospheric variability, rather than a direct teleconnection from the tropics. The precipitation anomalies in this region also stand out as being statistically significant if regressed onto the principal component time series of the first EOF of Z500 (not shown), so this link does not emerge simply as an artifact of the MCA method. It is plausible that the relatively weak precipitation anomalies in the eastern tropical Pacific are able to generate Rossby wave anomalies over the jet entrance region in the North Atlantic, which then trigger the observed storm-track anomalies and associated eddy feedback onto the large-scale circulation.

The variability of tropical precipitation and the extratropical circulation was also analyzed in an operational seasonal forecasting system, the ECMWF System 4. While System 4 is well able to reproduce and skillfully forecast the first EOF of tropical precipitation, the associated extratropical circulation anomalies found in the observations were largely absent in over the EuroAtlantic region in System 4. However, the simulated teleconnection appears to be reasonable along many regions in the extratropics, particularly over the Pacific. Barotropic model simulations linearized about the System 4 background state, which do a reasonable job of capturing the response of the full model, indicate that the poleward bias of the Asian/west Pacific jet stream hinders Rossby wave propagation from the tropical Pacific. This suggests that these biases are one of the reasons why the remote teleconnection between tropical Pacific precipitation and the Euro-Atlantic sector is not well reproduced in the System 4 seasonal forecasts. This indicates that there remains significant potential seasonal forecast skill that may not yet be realized in current seasonal forecasting systems.

Acknowledgments. We thank the three anonymous reviewers whose insightful comments greatly helped to improve the manuscript. We thank Cheikh Mbengue for useful comments that helped to shape this study. This work is part of the SummerTIME Project (NE/M005887/ 1), funded by the U.K. Natural Environment Research Council. GPCP data, NOAA ERSST V4 data, and NCEP-NCAR reanalysis data were all provided by the NOAA/OAR/ESRL PSD, Boulder, Colorado, from their website at http://www.esrl.noaa.gov/psd/. We are grateful to the European Centre for Medium-Range Weather Forecasts (ECMWF) for making the ERAInterim reanalysis data and System-4 hindcast data available. This work is was also supported in part by the ECMWF special project awarded to COR, titled "Assessing Sources of Seasonal Forecast Skill over Europe in Summer Using Relaxation Experiments."

\section{REFERENCES}

Adler, R. F., and Coauthors, 2003: The version-2 Global Precipitation Climatology Project (GPCP) Monthly Precipitation Analysis (1979-present). J. Hydrometeor., 4, 1147-1167, https://doi.org/10.1175/1525-7541(2003)004<1147: TVGPCP $>2.0 . \mathrm{CO} ; 2$.

Ambrizzi, T., B. J. Hoskins, and H.-H. Hsu, 1995: Rossby wave propagation and teleconnection patterns in the austral winter. J. Atmos. Sci., 52, 3661-3672, https://doi.org/10.1175/ 1520-0469(1995)052<3661:RWPATP $>2.0 . C O ; 2$.

Bladé, I., B. Liebmann, D. Fortuny, and G. J. van Oldenborgh, 2012: Observed and simulated impacts of the summer NAO in Europe: Implications for projected drying in the Mediterranean region. Climate Dyn., 39, 709-727, https://doi.org/ 10.1007/s00382-011-1195-x.

Brands, S., 2017: Which ENSO teleconnections are robust to internal atmospheric variability? Geophys. Res. Lett., 44, 14831493, https://doi.org/10.1002/2016GL071529.

Branstator, G., 1983: Horizontal energy propagation in a barotropic atmosphere with meridional and zonal structure. J. Atmos. Sci., 40,1689-1708, https://doi.org/10.1175/ 1520-0469(1983)040<1689:HEPIAB > 2.0.CO;2.

— and their seasonality. J. Atmos. Sci., 74, 1513-1532, https:// doi.org/10.1175/JAS-D-16-0305.1.

Bretherton, C. S., C. Smith, and J. M. Wallace, 1992: An intercomparison of methods for finding coupled patterns in climate data. J. Climate, 5, 541-560, https://doi.org/10.1175/ 1520-0442(1992)005<0541:AIOMFF>2.0.CO;2.

Cai, M., and M. Mak, 1990: Symbiotic relation between planetary and synoptic-scale waves. J. Atmos. Sci., 47, 2953-2968, https:// doi.org/10.1175/1520-0469(1990)047<2953:SRBPAS >2.0.CO;2.

Dee, D., and Coauthors, 2011: The ERA-Interim reanalysis: Configuration and performance of the data assimilation system. Quart. J. Roy. Meteor. Soc., 137, 553-597, https://doi.org/ 10.1002/qj.828.

Ding, Q., B. Wang, J. M. Wallace, and G. Branstator, 2011: Tropical-extratropical teleconnections in boreal summer: Observed interannual variability. J. Climate, 24, 1878-1896, https://doi.org/10.1175/2011JCLI3621.1.

Dong, B., R. T. Sutton, T. Woollings, and K. Hodges, 2013: Variability of the North Atlantic summer storm track: Mechanisms and impacts on European climate. Environ. Res. Lett., 8, 034037, https://doi.org/10.1088/1748-9326/8/3/034037. 
Donges, J. F., I. Petrova, A. Loew, N. Marwan, and J. Kurths, 2015: How complex climate networks complement eigen techniques for the statistical analysis of climatological data. Climate Dyn., 45, 2407-2424, https://doi.org/10.1007/s00382-015-2479-3.

Duchon, C. E., 1979: Lanczos filtering in one and two dimensions. J. Appl. Meteor., 18, 1016-1022, https://doi.org/10.1175/ 1520-0450(1979)018<1016:LFIOAT >2.0.CO;2.

Dunstone, N., D. Smith, A. Scaife, L. Hermanson, R. Eade, N. Robinson, M. Andrews, and J. Knight, 2016: Skilful predictions of the winter North Atlantic Oscillation one year ahead. Nat. Geosci., 9, 809-814, https://doi.org/10.1038/ngeo2824.

Enfield, D. B., A. M. Mestas-Nuñez, and P. J. Trimble, 2001: The Atlantic multidecadal oscillation and its relation to rainfall and river flows in the continental US. Geophys. Res. Lett., 28 , 2077-2080, https://doi.org/10.1029/2000GL012745.

Fischer, E. M., S. Seneviratne, P. Vidale, D. Lüthi, and C. Schär, 2007: Soil moisture-atmosphere interactions during the 2003 European summer heat wave. J. Climate, 20, 5081-5099, https://doi.org/10.1175/JCLI4288.1.

Folland, C. K., J. Knight, H. W. Linderholm, D. Fereday, S. Ineson, and J. W. Hurrell, 2009: The summer North Atlantic Oscillation: Past, present, and future. J. Climate, 22, 1082-1103, https://doi.org/10.1175/2008JCLI2459.1.

Gastineau, G., and C. Frankignoul, 2015: Influence of the North Atlantic SST variability on the atmospheric circulation during the twentieth century. J. Climate, 28, 1396-1416, https://doi.org/ 10.1175/JCLI-D-14-00424.1.

Ghosh, R., W. A. Müller, J. Baehr, and J. Bader, 2017: Impact of observed North Atlantic multidecadal variations to European summer climate: A linear baroclinic response to surface heating. Climate Dyn., 48, 3547-3563, https://doi.org/10.1007/ s00382-016-3283-4.

Greatbatch, R. J., and T. Jung, 2007: Local versus tropical diabatic heating and the winter North Atlantic Oscillation. J. Climate, 20, 2058-2075, https://doi.org/10.1175/JCLI4125.1.

Held, I. M., and I.-S. Kang, 1987: Barotropic models of the extratropical response to El Niño. J. Atmos. Sci., 44, 3576-3586, https://doi.org/ 10.1175/1520-0469(1987)044<3576:BMOTER >2.0.CO;2.

Hoskins, B. J., and D. J. Karoly, 1981: The steady linear response of a spherical atmosphere to thermal and orographic forcing. J. Atmos. Sci., 38, 1179-1196, https://doi.org/10.1175/ 1520-0469(1981)038<1179:TSLROA > 2.0.CO;2.

_ - and T. Ambrizzi, 1993: Rossby wave propagation on a realistic longitudinally varying flow. J. Atmos. Sci., 50, 1661-1671, https:// doi.org/10.1175/1520-0469(1993)050<1661:RWPOAR > 2.0.CO;2.

_ - I. N. James, and G. H. White, 1983: The shape, propagation and mean-flow interaction of large-scale weather systems. J. Atmos. Sci., 40, 1595-1612, https://doi.org/10.1175/ 1520-0469(1983)040<1595:TSPAMF $>2.0 . C O ; 2$.

Huang, B., and Coauthors, 2015: Extended reconstructed sea surface temperature version 4 (ERSST.v4). Part I: Upgrades and intercomparisons. J. Climate, 28, 911-930, https://doi.org/ 10.1175/JCLI-D-14-00006.1.

Karoly, D. J., 1983: Rossby wave propagation in a barotropic atmosphere. Dyn. Atmos. Oceans, 7, 111-125, https://doi.org/ 10.1016/0377-0265(83)90013-1.

Knight, J. R., R. J. Allan, C. K. Folland, M. Vellinga, and M. E. Mann, 2005: A signature of persistent natural thermohaline circulation cycles in observed climate. Geophys. Res. Lett., 32, L20708, https://doi.org/10.1029/2005GL024233.

_ C. K. Folland, and A. A. Scaife, 2006: Climate impacts of the Atlantic multidecadal oscillation. Geophys. Res. Lett., 33, L17706, https://doi.org/10.1029/2006GL026242.
Krishnamurti, T. N., L. Stefanova, and V. Misra, 2013: Tropical Meteorology: An Introduction. Springer-Verlag, 424 pp., https://doi.org/10.1007/978-1-4614-7409-8.

MacLachlan, C., and Coauthors, 2015: Global Seasonal forecast system version 5 (GloSea5): A high-resolution seasonal forecast system. Quart. J. Roy. Meteor. Soc., 141, 1072-1084, https://doi.org/10.1002/qj.2396.

Mak, M., and M. Cai, 1989: Local barotropic instability. J. Atmos. Sci., 46, 3289-3311, https://doi.org/10.1175/1520-0469(1989)046<3289: $\mathrm{LBI}>2.0 . \mathrm{CO} ; 2$.

Molteni, F., and Coauthors, 2011: The new ECMWF seasonal forecast system (System 4). ECMWF Tech. Memo. 656, European Centre for Medium-Range Weather Forecasts, 49 pp., https://www.ecmwf.int/en/elibrary/11209-new-ecmwf-seasonal-forecast-system-system-4.

North, G. R., T. L. Bell, R. F. Cahalan, and F. J. Moeng, 1982: Sampling errors in the estimation of empirical orthogonal functions. Mon. Wea. Rev., 110, 699-706, https://doi.org/ 10.1175/1520-0493(1982)110<0699:SEITEO > 2.0.CO;2.

O'Reilly, C. H., 2018: Interdecadal variability of the ENSO teleconnection to the wintertime North Pacific. Climate Dyn., 1-18, https://doi.org/10.1007/s00382-018-4081-y.

J. Heatley, D. MacLeod, A. Weisheimer, T. N. Palmer, N. Schaller, and T. Woollings, 2017a: Variability in seasonal forecast skill of northern hemisphere winters over the twentieth century. Geophys. Res. Lett., 44, 5729-5738, https://doi.org/ 10.1002/2017GL073736.

, T. Woollings, and L. Zanna, 2017b: The dynamical influence of the Atlantic Multidecadal Oscillation on continental climate. J. Climate, 30, 7213-7230, https://doi.org/10.1175/ JCLI-D-16-0345.1.

Park, S., 2004: Remote ENSO influence on Mediterranean sky conditions during late summer and autumn: Evidence for a slowly evolving atmospheric bridge. Quart. J. Roy. Meteor. Soc., 130, 2409-2422, https://doi.org/10.1256/qj.03.62.

Petrie, R. E., L. C. Shaffrey, and R. T. Sutton, 2015: Atmospheric response in summer linked to recent Arctic sea ice loss. Quart. J. Roy. Meteor. Soc., 141, 2070-2076, https://doi.org/10.1002/qj.2502.

Riddle, E. E., A. H. Butler, J. C. Furtado, J. L. Cohen, and A. Kumar, 2013: CFSv2 ensemble prediction of the wintertime Arctic Oscillation. Climate Dyn., 41, 1099-1116, https://doi.org/ 10.1007/s00382-013-1850-5.

Ropelewski, C. F., and M. S. Halpert, 1987: Global and regional scale precipitation patterns associated with the El Niño/ Southern Oscillation. Mon. Wea. Rev., 115, 1606-1626, https://doi. org/10.1175/1520-0493(1987)115<1606:GARSPP>2.0.CO;2.

Sardeshmukh, P. D., and B. J. Hoskins, 1988: The generation of global rotational flow by steady idealized tropical divergence. J. Atmos. Sci., 45, 1228-1251, https://doi.org/ 10.1175/1520-0469(1988)045<1228:TGOGRF $>2.0$. CO;2.

Scaife, A. A., and Coauthors, 2014: Skillful long-range prediction of European and North American winters. Geophys. Res. Lett., 41, 2514-2519, https://doi.org/10.1002/2014GL059637.

— , and Coauthors, 2017: Tropical rainfall, Rossby waves and regional winter climate predictions. Quart. J. Roy. Meteor. Soc., 143, 1-11, https://doi.org/10.1002/qj.2910.

Schneidereit, A., S. Schubert, P. Vargin, F. Lunkeit, X. Zhu, D. H. Peters, and K. Fraedrich, 2012: Large-scale flow and the longlasting blocking high over Russia: Summer 2010. Mon. Wea. Rev., 140, 2967-2981, https://doi.org/10.1175/MWR-D-11-00249.1.

Screen, J. A., 2013: Influence of Arctic sea ice on European summer precipitation. Environ. Res. Lett., 8, 044015, https://doi.org/ 10.1088/1748-9326/8/4/044015. 
Shaman, J., 2014a: The seasonal effects of ENSO on atmospheric conditions associated with European precipitation: Model simulations of seasonal teleconnections. J. Climate, 27, 1010 1028, https://doi.org/10.1175/JCLI-D-12-00734.1.

_ 2014b: The seasonal effects of ENSO on European precipitation: Observational analysis. J. Climate, 27, 6423-6438, https://doi.org/10.1175/JCLI-D-14-00008.1.

, and E. Tziperman, 2007: Summertime ENSO-North African-Asian Jet teleconnection and implications for the Indian monsoons. Geophys. Res. Lett., 34, L11702, https:// doi.org/10.1029/2006GL029143.

—_, and —, 2011: An atmospheric teleconnection linking ENSO and southwestern European precipitation. J. Climate, 24, 124-139, https://doi.org/10.1175/2010JCLI3590.1.

— and _ 2016: The superposition of eastward and westward Rossby waves in response to localized forcing. J. Climate, 29, 7547-7557, https://doi.org/10.1175/JCLI-D-16-0119.1.

— S. K. Esbensen, and E. D. Maloney, 2009: The dynamics of the ENSO-Atlantic hurricane teleconnection: ENSO-related changes to the North African-Asian jet affect Atlantic basin tropical cyclogenesis. J. Climate, 22, 2458-2482, https://doi.org/ 10.1175/2008JCLI2360.1.

Smith, D. M., A. A. Scaife, and B. P. Kirtman, 2012: What is the current state of scientific knowledge with regard to seasonal and decadal forecasting? Environ. Res. Lett., 7, 015602, https:// doi.org/10.1088/1748-9326/7/1/015602.

Stockdale, T. N., F. Molteni, and L. Ferranti, 2015: Atmospheric initial conditions and the predictability of the Arctic Oscillation. Geophys. Res. Lett., 42, 1173-1179, https://doi.org/ 10.1002/2014GL062681.

Sutton, R. T., and D. L. Hodson, 2005: Atlantic Ocean forcing of North American and European summer climate. Science, 309, 115-118, https://doi.org/10.1126/science.1109496.
, and B. Dong, 2012: Atlantic Ocean influence on a shift in European climate in the 1990s. Nat. Geosci., 5, 788-792, https://doi.org/10.1038/ngeo1595.

Trenberth, K. E., G. W. Branstator, D. Karoly, A. Kumar, N.-C. Lau, and C. Ropelewski, 1998: Progress during TOGA in understanding and modeling global teleconnections associated with tropical sea surface temperatures. J. Geophys. Res., 103, 14291-14324, https://doi.org/ 10.1029/97JC01444.

Weisheimer, A., and T. Palmer, 2014: On the reliability of seasonal climate forecasts. J. Roy. Soc. Interface, 11, 20131162, https:// doi.org/10.1098/rsif.2013.1162.

—_, N. Schaller, C. O'Reilly, D. A. MacLeod, and T. Palmer, 2017: Atmospheric seasonal forecasts of the twentieth century: Multi-decadal variability in predictive skill of the winter North Atlantic Oscillation (NAO) and their potential value for extreme event attribution. Quart. J. Roy. Meteor. Soc., 143, 917-926, https://doi.org/10.1002/ qj. 2976.

Wu, B., R. Zhang, R. D'Arrigo, and J. Su, 2013: On the relationship between winter sea ice and summer atmospheric circulation over Eurasia. J. Climate, 26, 5523-5536, https://doi.org/ 10.1175/JCLI-D-12-00524.1.

Xie, P., and P. A. Arkin, 1997: Global precipitation: A 17-year monthly analysis based on gauge observations, satellite estimates, and numerical model outputs. Bull. Amer. Meteor. Soc., 78, 2539-2558, https://doi.org/10.1175/1520-0477(1997)078<2539: GPAYMA $>2.0 . \mathrm{CO} ; 2$.

Yiou, P., and J. Cattiaux, 2013: Contribution of atmospheric circulation to wet north European summer precipitation of 2012 [in "Explaining Extreme Events of 2012 from a Climate Perspective"]. Bull. Amer. Meteor. Soc., 94, S39-S41, https://doi.org/ 10.1175/BAMS-D-13-00085.1. 